\title{
CLASICISMO, NEOMEDIEVALISMO Y ECLECTICISMO EN LA OBRA DE DOMINGO RODRÍGUEZ SESMERO COMO ARQUITECTO DIOCESANO DE TUI Y SANTIAGO DE COMPOSTELA (1882-1897)
}

\author{
MARTA GARCÍA FILGUEIRA*
}

\begin{abstract}
Resumen
Con el presente artículo se pretende contribuir al conocimiento de la actividad arquitectónica de Domingo Rodríguez Sesmero en Galicia durante el último tercio del siglo XIX. En concreto es la faceta como arquitecto diocesano de Tui y de Santiago de Compostela la que es aquí analizada. Para ello se contextualiza dicha actividad dentro del marco de la recuperación de la edilicia religiosa en España durante los años de la Restauración borbónica. Se enfoca el estudio desde un punto de vista estilístico, valorando la obra de Domingo Rodríguez Sesmero dentro del contexto del historicismo del siglo XIX en Galicia y su relación con modelos foráneos. Se analizan también los aspectos relativos a la conservación y restauración arquitectónica de los templos gallegos teniendo en cuenta las ideas sobre el patrimonio construido propias del último tercio del XIX.
\end{abstract}

\section{Palabras Clave}

Domingo Rodríguez Sesmero, arquitectura, arquitectos diocesanos, eclecticismo, historicismo, clasicismo, restauración, patrimonio.

\begin{abstract}
With the present article we try to contribute to the knowledge of the architectural work of Domingo Rodríguez Sesmero in Galice during the last thirty years of the XIX ${ }^{\text {th }}$ century. It is his work as a diocesan architect of Tui and Santiago de Compostela which we study here, in the context of the process of recovering of the religious architecture in Spain during the political period of the restoration of the Spanish monarchy. We focus the study from the stylistic point of view, attending to the movement of historicism caracteristic of that period in Europe, Spain and Galice. We analyse aswell the aspects regarding architectural preservation and restoration in Galice and it's relation with european models.
\end{abstract}

\section{Key Words}

Domingo Rodríguez Sesmero, architecture, diocesan architects, eclecticism, historicism, classicism, restoration, art heritage.

* Marta García Filgueira es licenciada en Historia del Arte por la Universidad de Santiago. Actualmente está preparando para publicar su Tesis Doctoral acerca de la obra arquitectónica de Domingo Rodríguez Sesmero y Alejandro Rodríguez-Sesmero González. 
on el presente artículo se pretende contribuir al conocimiento de la obra de Domingo Rodríguez Sesmero, hasta ahora apenas estudiada. Este arquitecto vallisoletano trabajó en Galicia durante el último cuarto del siglo XIX dedicado tanto a la arquitectura institucional como a la privada, de las que tenemos ejemplos en numerosos puntos de la geografía gallega ${ }^{1}$. El estudio de su obra como arquitecto diocesano de Tui y Santiago se concibe como aportación al conocimiento de la arquitectura religiosa de los últimos veinte años del siglo XIX, permitiendo analizar el proceso de introducción en Galicia de las corrientes estilísticas historicistas y eclecticistas en boga a finales del siglo XIX en el resto de España y en toda Europa. Es además el momento en que se asimilan en España y en Galicia las teorías sobre restauración y conservación arquitectónicas formuladas a lo largo del siglo en Francia, Inglaterra e Italia, con lo que se van afianzando en nuestro país las investigaciones científicas -arqueología e historia de los estilos arquitectónicos- $\mathrm{y}$ consecuentemente se van perfilando los criterios de intervención sobre el patrimonio monumental, que se aplican en primer lugar al patrimonio eclesiástico $^{2}$. El período de la Restauración estuvo definido por unas relaciones IglesiaEstado mejoradas con respecto al resto del siglo, tanto en España como en Galicia ${ }^{3}$. Esto supondrá una recuperación de la edilicia religiosa, que había entrado en crisis con los procesos desamortizadores ${ }^{4}$. Esta recuperación se había iniciado lentamente a partir del Concordato de 1851, en virtud del cual la Iglesia obtenía del Estado ayudas para la reparación y edificación de templos 5 .

${ }^{1}$ Proporcionan noticias sobre este arquitecto y su obra en Galicia: NAVASCUÉS PALACIO, P. (1984), 18 y 98. FERNÁNDEZ FERNÁNDEZ, X. (1995), 145, 273 y ss., 276 y ss., 283 y ss., 284 y ss. FERNÁNDEZ FERNÁNDEZ, X. (1996), 340; SÁNCHEZ GARCÍA, J.A. (1996), 445-449; SÁNCHEZ GARCÍA, J.A. (1997), 20, 21, 125; GARRIDO RODRÍGUEZ, X. (2000), 165, 178; GARRIDO RODRÍGUEZ, X. e IGLESIAS VEIGA, X.R. (2001), 55-66, 139, 141, 142, 143, 144, 173-199.

${ }^{2}$ Sobre la evolución de los criterios de intervención en los monumentos españoles desde el siglo XIX veánse CAPITEL, A. (1988); ORDIERES DÍEZ, I. (1995); GONZÁLEZ-VARAS IBÁÑEZ, I. (1996); GONZÁLEZ-VARAS IBÁÑEZ, I. (1999).

${ }^{3}$ BARREIRO FERNÁNDEZ, X.R. (1997), 313.

${ }^{4}$ RUEDA, G. (1996), 66.

${ }^{5}$ ORDIERES DÍEZ, I. (1995), 65. 


\section{EL ARQUITECTO DIOCESANO EN GALICIA EN EL ÚLTIMO CUARTO DEL SIGLO XIX}

La figura de Arquitecto Diocesano se crea en España por el R.D. de 13 de Agosto de 1876. Dependientes del Ministerio de Gracia y Justicia, que era el que los nombraba, estos profesionales trabajaban al servicio de las Juntas Diocesanas para Construcción y Reparación de Templos y edificios eclesiásticos ${ }^{6}$. Estaban mal retribuidos, lo que impedía su dedicación exclusiva -no tenían sueldo fijo, sus honorarios se fijaron en la mitad de lo estipulado para una obra particular-y tenían que gestionar expedientes mediante un complicado sistema de tramitación, lo que unido a la gran cantidad de edificios a su cuidado y la dificultad de inspeccionarlos adecuadamente dados los escasos medios de transporte de la época hacía que su labor fuese lenta y dificultosa ${ }^{7}$. El Real Decreto disponía que: «Los arquitectos diocesanos no tendrán sueldo fijo sino cuando por la importancia de la obra cuyo proyecto ó dirección se les encomiende, se considere conveniente y económico señalarles dotación anual, mientras duren los trabajos. En los demás casos percibirán honorarios con arreglo á tarifa, entendiéndose que no excederán de la mitad de los señalados para obras en edificios particulares; abonándoseles además los gastos de viaje cuando presten servicio fuera del lugar de su ordinaria residencia» ${ }^{8}$. La reparación y construcción de templos y edificios eclesiásticos regulada por este decreto dependía de fondos estatales -desde el Concordato de 1851 el estado se había comprometido a costear las reparaciones de templos (artículo 36) y por la Ley de 4 de abril de 1860 , que puso en vigor lo acordado en el Convenio adicional con la Santa Sede de 25 de Agosto de 1859, a construir a sus expensas las iglesias de nueva

\footnotetext{
${ }^{6}$ La composición de las Juntas se reguló por el Real Decreto de 4 de octubre de 1861. Se componían de: «el prelado, y en Sede vacante ó impedida, del gobernador de la diócesis, presidente; del deán; de un canónigo, elegido por el cabildo; de un párroco con residencia en la población, designado por el prelado; del promotor fiscal, y donde hubiere más de uno del más antiguo; del síndico del Ayuntamiento, y de un individuo nombrado por la Comisión provincial de monumentos». R.D. 13 Agosto de 1876, art. 5º, recogido en MARTÍNEZ ALCUBILLA, M. (1893), Tomo VI, 501-512.

${ }^{7}$ ORDIERES DÍEZ, I. (1995), 44.

${ }^{8}$ R.D. de 13 de Agosto de 1876, art. 9. MARTÍNEZ ALCUBILLA, M, (1893), 504.
} 
planta que fueran necesarias ${ }^{9}$ - fondos que eran casi siempre escasos para las obras a realizar ${ }^{10}$.

En cuanto a los problemas estilísticos y constructivos planteados a un arquitecto diocesano a la hora de enfrentarse a la restauración de edificios eclesiásticos, hay que tener en cuenta que en España, durante la segunda mitad del siglo XIX, fue la influencia de Viollet-le-Duc y sus ideas de restauración en estilo ${ }^{11}$ las que se impusieron $^{12}$, no siendo hasta finales de siglo cuando empiezan a afianzarse las corrientes conservacionistas derivadas de las ideas del inglés John Ruskin y del italiano Camillo Boito ${ }^{13}$. La postura de la Real Academia de Bellas Artes de San Fernando evoluciona, a partir de los años setenta, desde la falta de criterios sólidos hacia una postura conservacionista ${ }^{14}$.

En Galicia había entonces cinco diócesis: Lugo, Mondoñedo-Ferrol, Santiago de Compostela, Ourense y Tui. Los puestos de arquitectos de estas cinco diócesis durante el último cuarto del siglo XIX fueron ocupados con frecuencia por los mismos arquitectos que ocupaban simultáneamente los cargos de arquitectos municipales o provinciales. Esto fue debido a que, como se señaló más arriba, la remuneración de los arquitectos diocesanos era escasa. La mayor parte de estos arquitectos que trabajaban en Galicia al servicio de las instituciones municipales, provinciales o estatales -ya se ha dicho que los arquitectos diocesanos dependían del Ministerio de Gracia y Justicia- eran foráneos. Se dió en la segunda mitad del siglo XIX una gran afluencia hacia Galicia de arquitectos oriundos de otros puntos de España, tendencia que se incrementó durante la primera etapa de la Restaura-

${ }^{9}$ El artículo 36 del Concordato de 1851 y el artículo 13 del Convenio adicional de 1859, se desarrollaron posteriormente, en el R.D. de 4 de octubre de 1861. En este Real Decreto se legisló la creación de las Juntas Diocesanas para la gestión de los expedientes y se dividían las intervenciones relativas al patrimonio arquitectónico de la iglesia en ordinarias y extraordinarias. El R.D. de 13 de Agosto de 1876 reorganizó las Juntas, que a partir de entonces pasaron a denominarse Juntas Diocesanas de construcción y reparación de templos y edificios eclesiásticos, que eran auxiliares del gobierno en la instrucción de los expedientes de obras extraordinarias. Creó la figura de Arquitecto Diocesano (artículo $8^{\circ}$ ) y dictó las nuevas reglas a las que debían someterse las obras de construcción y reparación de templos. ORDIERES DÍEZ, I. (1995), 65, 66.

${ }^{10}$ «(...) es indispensable dictar reglas para que el crédito legislativo se emplee de la mejor manera posible, acudiendo con preferencia a lo que más apremie y aplazando para época más próspera lo que con menos inconvenientes pueda demorarse». R.D. 13 de Agosto de 1876. Ibídem.

${ }^{11}$ VIOLLET-LE-DUC, E. (1854-1869), veáse la entrada «Restauration», Tomo VIII, 14-34.

${ }^{12}$ ORDIERES DÍEZ, I. (1995), 126; GONZÁLEZ-VARAS, I. (1996), 83, 126.

${ }^{13}$ ORDIERES DÍEZ, I. (1995), 138; GONZÁLEZ-VARAS, I. (1996), 68, 75, 80, 83 y ss. Véase también GONZÁLEZ-VARAS IBÁÑEZ, I. (1999).

${ }^{14}$ ORDIERES DÍEZ, I. (1995), 132; GONZÁLEZ-VARAS IBÁÑEZ, I. (1999), 177.

Cuadernos de Estudios Gallegos, Tomo LII, Fascículo 118, Santiago 2005. (Págs. 305 - 345) 
ción cuando llegaron a Galicia numerosos profesionales formados en la Escuela de Arquitectura de Madrid ${ }^{15}$. Sus trabajos como arquitectos diocesanos se conocen hasta el momento de forma limitada ${ }^{16}$. Algunos arquitectos diocesanos en el tercer tercio del siglo XIX en las diócesis gallegas fueron ${ }^{17}$ : Antonio Bermejo y Arteaga (diócesis de Santiago), Juan de Ciórraga, (diócesis de Santiago), Faustino Domínguez Domínguez (diócesis de Santiago), Faustino Domínguez Coumes-Gay (diócesis de Santiago), Manuel Hernández y Álvarez Reyero (diócesis de Santiago), Antonio de Mesa (diócesis de Santiago), Pedro Mariño y Ortega (diócesis de Santiago), Nemesio Cobreros y Cuevillas (diócesis de Lugo y diócesis de Mondoñedo-Ferrol), Daniel García Vaamonde (diócesis de Ourense), Daniel Vázquez Gulías Martínez (diócesis de Ourense), José Antonio Queralt Rauret (diócesis de Ourense), Justino Flórez Llamas (diócesis de Tui), Manuel Felipe Quintana (diócesis de Tui), Domingo Rodríguez Sesmero (diócesis de Tui y diócesis de Santiago).

\section{DOMINGO RODRÍGUEZ SESMERO}

La trayectoria vital de este arquitecto permanece aún en gran parte sin esclare$\operatorname{cer}^{18}$, ya que no se ha precisado todavía el lugar o lugares en los que pudo haber residido entre el año 1833 en que se titula en Valladolid y el año 1863, en que solicita la plaza de arquitecto municipal de la misma ciudad. Nuestras investigaciones en curso apuntan la posibilidad de que estuviese en Asturias entre esas fechas.

Domingo Rodríguez Sesmero nació en Medina del Campo el 4 de Agosto de $1811^{19}$. Estudió en la Real Academia de Matemáticas y Nobles Artes de la Purísi-

\footnotetext{
${ }^{15}$ FERNÁNDEZ FERNÁNDEZ, X. (1995), 389.

${ }^{16}$ Noticias generales y análisis de algunas obras con representación de todas las diócesis de Galicia se dan en el libro de FERNÁNDEZ FERNÁNDEZ, X. (1995). Por su parte SÁNCHEZ GARCÍA, J.A. (1997) estudia detalladamente toda la actividad de Faustino Domínguez Domínguez al servicio de la Iglesia en la diócesis de Santiago. ABEL VILELA, A de. (1996) estudia algunas de las obras realizadas por Nemesio Cobreros, diocesano de Mondoñedo-Ferrol y Lugo.

${ }^{17}$ Datos tomados (excepto el relativo a Justino Flórez Llamas) de FERNÁNDEZ FERNÁNDEZ, X. (1995), 332-397 y FERNÁNDEZ FERNÁNDEZ, X. (1996), 340.

${ }^{18}$ Los datos más completos están en la reciente obra de GARRIDO RODRÍGUEZ, X. e IGLESIAS VEIGA, X.R. (2001), 174 y ss.

${ }^{19}$ Archivo Diocesano de Valladolid (A.D.V.), Libro de Bautizados, Medina del Campo, parroquia de San Antolín.
} 
ma Concepción de Valladolid, donde aprobó el examen de arquitectura en $1833^{20}$. Se le convalidó el título de arquitecto el 5 de Abril de 1849 por el Ministerio de Comercio, Instrucción y Obras Públicas ${ }^{21}$. En más de una ocasión a lo largo de su carrera va a tener que enfrentarse a cuestionamientos por parte de otros profesionales acerca de la validez de su titulación. En 1869, siendo arquitecto provincial de Valladolid, fue denunciado por un colega que solicitó al Ministerio su inhabilitación profesional, petición que no prosperó, ya que se resolvió que la titulación de Sesmero era válida. Los problemas tenían su origen en una supuesta irregularidad en la composición del tribunal que lo había examinado en la Academia de Valladolid, que no habría contado con el número de profesores de arquitectura a que obligaba la normativa que hacía cumplir la Academia de San Fernando ${ }^{22}$. Domingo R. Sesmero fue arquitecto municipal de Valladolid entre julio de $1863^{23}$ y mayo de $1864^{24}$. Fue también arquitecto provincial de la misma provincia entre $1866^{25} \mathrm{y}$ $1869^{26}$.

Encuadrable en la última generación de arquitectos académicos, su larga carrera profesional se extiende desde la muerte de Fernando VII al cambio de siglo. Su obra se debate entre las concepciones clasicistas iniciales adquiridas durante su formación en la Academia de Valladolid y el historicismo y eclecticismo presentes en el ambiente, introducidos en España a partir de mediados de siglo por las primeras promociones de arquitectos formados en la Escuela de Arquitectura de Ma$\mathrm{drid}^{27}$. Estas primeras promociones formadas en la Escuela tuvieron como profeso-

${ }^{20}$ Archivo de la Real Academia de Bellas Artes de la Purísima Concepción de Valladolid (A.R.A.V.) Libro $2^{\circ}$ de Actas de las Juntas Ordinarias. Sesmero fue aprobado en la sesión de 4 y 5 de mayo de 1833

${ }^{21}$ Archivo General de la Administración. Alcalá de Henares (A.G.A). Títulos de Arquitectos. C15072/11. Expediente sobre inhabilitación para ejercer la Arquitectura a D. Domingo Rodríguez Sesmero. 1869.

${ }^{22}$ Ibídem, ibídem.

${ }^{23}$ Archivo Municipal de Valladolid (A.M.V.). Urbanismo. C-395/109. Expediente de provisión de la plaza de Arquitecto Municipal, y nombramiento de Domingo Rodríguez Sesmero como tal.

${ }^{24}$ A.M.V. Urbanismo. C-396/27. Expediente en virtud del cual se aprueban las tarifas de honorarios correspondientes al arquitecto municipal, y se nombra a José María Ortiz para ocupar dicha plaza. 1864.

${ }^{25}$ Diputación Provincial de Valladolid. Secretaría. Actas del Pleno, sesión de 21 de octubre de 1866. Para más datos consultar: A.G.A. Sección E.C.Leg. 9641/59. Nombramiento de Domingo Rodríguez Sesmero como Arquitecto Provincial.

${ }^{26}$ Diputación Provincial de Valladolid. Secretaría. Actas del Pleno, sesión de 7 de abril de 1869.

${ }^{27}$ Sobre la relación entre la formación académica y la formación en la Escuela veáse HERNANDO, J. (1989), 168 y ss. Véase también NAVASCUÉS PALACIO, P. (1973), 95 y ss. 
res a varios arquitectos de la última generación académica, algunos de los cuales ya empezaban a mostrarse sensibles a la arquitectura medieval, que descubren a través de la literatura romántica ${ }^{28}$.

Domingo Rodríguez Sesmero obtiene su título sólo dos años después que Aníbal Álvarez Bouquel (1806-1870), es sólo cuatro años más joven que Narciso Pascual y Colomer (1808-1870), y sin embargo su vida profesional abarca casi treinta años más que la de estos dos arquitectos pertenecientes a la última generación académica. Nace un año antes que Juan Bautista Peyronnet (1812-1875), que fue el autor de la fachada neogótica de la catedral de Palma de Mallorca, entre 1852 y 1875. Este arquitecto sin embargo también desaparece cuando todavía faltaban casi diez años para que Sesmero empezara su labor como arquitecto diocesano. Es por ello que si las obras de la primera etapa de su carrera podrían ser analizadas desde la comparación con aquéllas de los citados arquitectos y otros de similar formación académica, la etapa final, a la que corresponden los edificios estudiados en este artículo, quedaría ya bajo influencias posteriores. Su carrera sí sería paralela, al menos en su discurrir cronológico, a la de José Oriol Mestres Esplugas (18151895), titulado en 1841 (ocho años después que Sesmero) en la Escuela de la Lonja de Barcelona y autor de varios proyectos para la terminación de la catedral de esa capital en 1860,1863 y $1888^{29}$. A propósito de la larga vida activa de arquitectos como Mestres, Navascués señaló la función que cumplieron de «enlace entre los arquitectos académicos de su generación y los formados en la Escuela de Arquitectura que trabajaron en la Barcelona de la Restauración» y el "desdoble de expresión que estos arquitectos hubieron de desempeñar $»^{30}$. Por otra parte, la gran mayoría de los arquitectos que participan en las grandes obras de restauración monumental neomedievalista en España en la segunda mitad del siglo, pertenecen a generaciones posteriores a la de Sesmero: Juan de Madrazo y Kuntz (1829-1881), Demetrio de los Ríos y Serrano (1827-1892), Ricardo Velázquez Bosco (18431923), Arturo Mélida Alinari (1849-1902), Juan Bautista Lázaro (1849-1919), Vicente Lampérez y Romea (1861-1923) o Manuel Aníbal Álvarez (1850-1930) entre otros. Tampoco eran de su generación los autores de los más significativos proyectos de iglesias neomedievales de nueva planta en la España de la Restauración, como el marqués de Cubas (1826-1899), autor del proyecto para la catedral de la Almudena en Madrid, Antonio de Paula del Villar (1828-1903), con su pro-

\footnotetext{
${ }^{28}$ NAVASCUÉS PALACIO, P. (1993), 212.

${ }^{29}$ GONZÁLEZ VARAS, I. (1996), 144 y ss.

${ }^{30}$ NAVASCUÉS PALACIO, P. (1993), 233.
} 
yecto para la Sagrada Familia de Barcelona o Federico Aparici (1832-1917), con el suyo para la colegiata de Covadonga. ${ }^{31}$

Domingo R. Sesmero desarrolló la última parte de su carrera profesional en Galicia, desde los años 70 del siglo XIX en que llega a Vigo, hasta su muerte en A Coruña en $1899^{32}$. Fue arquitecto municipal de Vigo entre $1873^{33}$ y 1875 , año en que deja el cargo por problemas de salud ${ }^{34}$. Volverá a ocupar este mismo puesto entre los años 1881 y $1886^{35}$. Fue arquitecto diocesano de Tui entre 1882 y $1886^{36}$ y de Santiago entre $1884^{37}$ y $1897^{38}$.

${ }^{31}$ Sería interesante también tener en cuenta su relación generacional con los arquitectos y teóricos franceses contemporáneos. Domingo Rodríguez Sesmero nace cuatro años después que Lassus (1807-1857), aunque vive unos cuarenta años más que él. Es tres años más joven que Viollet-le-Duc (1814-1879) quien además de haber sịdo el principal teórico de la restauración monumental en Francia, ocupó el cargo de Inspecteur Géneral du Service des Édifices Diocésains desde 1853 hasta 1874. MIDDLETON, R. Y WATKIN, D. (1979), 350, 352. Las ideas restauradoras de Viollet-leDuc tuvieron repercusión en toda Europa y abrieron el camino de la arquitectura contemporánea. Viollet-le-Duc fue nombrado académico honorario por la Real Academia de Bellas Artes de San Fernando en 1868. GONZÁLEZ-VARAS IBÁÑEZ, I. (1999), 170 y 175.

${ }^{32}$ Archivo Histórico Municipal de A Coruña (A.H.M.C.) Padrón de habitantes, 1899. C-1421. En 1894 aparece empadronado en A Coruña. (A.H.M.C.) Padrón municipal, año 1894. El último documento conocido firmado por Domingo Rodríguez Sesmero data de 31 de enero de 1898. A.H.D.S. Fondo general. Templos. C-1260. Expediente de reparación extraordinaria del Templo parroquial de Santiago de Puentedeume.

${ }^{33}$ Fue nombrado arquitecto municipal de Vigo el 10 de Julio de 1873, con un sueldo de 1.500 ptas. anuales. Ya había colaborado con el ayuntamiento en varias ocasiones con anterioridad. Archivo Municipal de Vigo. (A.M.Vi.). Actas Municipales-1873, sesión 10 de julio, folio 95. Las primeras noticias de Domingo R Sesmero en Vigo se remontan al año 1871, cuando ya interviene en algunas obras particulares. A.M.V. Urbanismo. Obras particulares, C-128, Expediente promovido a instancia de Guillermo Perincil sobre colocación de unas aceras de cantería alrededor de su casa en la calle Lage.

${ }^{34}$ A.M.Vi. Actas Municipales-1875. Sesión de 13 de mayo de 1875, f. 51 v.

${ }^{35}$ A.M.Vi. Actas Municipales. Sesión 24 de marzo de 1881 f. 44 y 16 de setiembre de 1886, f. $122 \mathrm{v}$.

${ }^{36}$ Sesmero sucede en el cargo a Justino Flórez Llamas en 1882. La primera aparición de Sesmero en los documentos como arquitecto de la diócesis de Tui se refiere al reconocimiento del templo de San Miguel de Ponteareas, que realiza en Agosto de 1882. Archivo Histórico Diocesano de TuiVigo (A.H.D.T-V). Parroquia de San Miguel de Ponteareas. Expediente de Construcción de la Iglesia Parroquial (1878-1892). Sesmero tomaría posesión del cargo de arquitecto diocesano de Tui en setiembre de 1882 y lo dejaría en setiembre de 1886. Faro de Vigo, 24 setiembre de 1882 y Faro de Vigo, 20 de setiembre de 1886 (citados en FERNÁNDEZ FERNÁNDEZ, X. -1995-).

${ }^{37}$ Domingo R. Sesmero sucede en el puesto a Faustino Domínguez Coumes-Gay, que ocupaba la plaza de forma interina tras la renuncia de su padre Faustino Domínguez Domínguez. SÁNCHEZ GARCÍA, J.A. (1997), 125. Durante la primera fase del expediente de construcción de Santiago de Viascón se da el cambio de arquitecto entre Coumes-Gay y Sesmero. Archivo Histórico Diocesano 
En la Galicia de ese último cuarto del siglo XIX se encontraban en activo todavía algunos arquitectos formados en la Academia, como Faustino Domínguez Domínguez (1817-1890), cuya obra permaneció apegada a esquemas clasicistas, evolucionando, aunque tardía y parcialmente hacia el lenguaje ecléctico ${ }^{39}$. Pero, en los años de la Restauración, por las circunstancias de calma y estabilidad política unidas a la recuperación económica iniciada desde finales del reinado de Isabel II, se había creado en Galicia un «clima adecuado para la realización de obras de arquitectura ${ }^{40}$. Comenzaría ya hacia 1864-67 el momento de proliferación del movimiento ecléctico y de las alternativas historicistas ${ }^{41}$. Durante la Restauración, la mayor parte de las obras institucionales fueron realizadas por profesionales formados en la Escuela de Arquitectura de Madrid, que llegan a Galicia atraídos por los cargos municipales, provinciales y diocesanos y renuevan la arquitectura ${ }^{42}$. Paralelamente se desarrolla la obra de numerosos maestros de obras con formación determinada también por el eclecticismo, que viven en estos años de finales de siglo su época dorada ${ }^{43}$, como Gabriel Vitini, Manuel Riva de Soto, o el propio hijo de Domingo R. Sesmero, Alejandro Rodríguez-Sesmero González, entre otros ${ }^{44}$.

En este contexto, ¿cuál sería la formación de Sesmero en historia de los estilos arquitectónicos y hasta qué punto estaría en contacto con las investigaciones arqueológicas sobre el patrimonio que comenzaron en España en los años cuarenta $^{45}$ ? ¿En qué medida un arquitecto que desarrolla su actividad lejos de Madrid recibiría la influencia de las últimas ideas y modas en intervención sobre el patrimonio arquitectónico durante los años de la Restauración? ¿Qué publicaciones podía consultar? Intentando dar respuesta a alguna de estas cuestiones, podemos

\footnotetext{
de Santiago. (A.H.D.S.). Fondo general. Templos. C-1247, expediente de reconstrucción de la iglesia parroquial de Santiago de Viascón. 1886-1893.

${ }^{38}$ En 1897 le sucede en el cargo Antonio de Mesa (abandonándolo a los pocos meses) y a continuación Manuel Hernández y Álvarez Reyero. A.H.D.S. Fondo general. Templos. C-1260, expediente sobre reparación extraordinaria del Templo parroquial de Santiago de Pontedeume.

${ }^{39}$ SÁNCHEZ GARCÍA, J.A. (1997), 22.

${ }^{40}$ VIGO TRASANCOS, A. (1990), 328.

${ }^{41}$ Ibídem, 331.

${ }^{42}$ LÓPEZ VÁZQUEZ, J.M. (1995), 140

${ }^{43}$ SÁNCHEZ GARCÍA, J.A. (2001), 193 y ss.

${ }^{44}$ Ibídem.

${ }^{45}$ Los primeros intentos de periodización de la arquitectura española se dieron en el año 1848 por parte de la Comisión Central de Monumentos y hombres a ella vinculados como José Caveda y Nava, que publicó en ese año su Ensayo histórico sobre los diversos géneros de Arquitectura empleados en España desde la dominación romana hasta nuestros dias. ORDIERES DÍEZ, I. (1995), 78. Véase también HENARES CUÉLLAR, I. (1982), 161-164.
} 
decir que Domingo Rodríguez Sesmero contaba con cierta experiencia previa en el campo de la conservación monumental, aunque sólo fuera la adquirida durante los tres años en que fue miembro de la Comisión Provincial de Monumentos Históricos y Artísticos de Valladolid, en los años sesenta, cuando era arquitecto provincial $^{46}$. Es muy posible que entonces conociese el Ensayo histórico sobre los diversos géneros de Arquitectura empleados en España desde la dominación romana hasta nuestros dias, escrito por José Caveda y Nava y publicado en $1848^{47}$, o también el Boletín Español de Arquitectura, publicado a partir de 1846, en el que se trataban problemas relacionados con la actividad arqueológica al servicio del conocimiento del patrimonio y de su conservación y restauración ${ }^{48}$. Después, a través de su hijo, Alejandro Rodríguez-Sesmero González, titulado maestro de obras por la Escuela Especial de Arquitectura de Madrid en 1871, pudo entrar en contacto con las ideas historicistas y eclecticistas adoptadas por las nuevas generaciones.

\section{ACTIVIDAD COMO ARQUITECTO DIOCESANO}

Como arquitecto diocesano, Domingo R. Sesmero realiza dos tipos de trabajos: reparaciones -que pueden llegar a incluir reedificación de parte de la estructura- $\mathrm{y}$ templos de nueva planta. Utiliza dos lenguajes: el clasicista y el neomedieval, ambos aplicados con una gran simplicidad de diseño y austeridad ornamental condicionado sin duda por las limitaciones presupuestarias. Al estilo clasicista recurre en la mayor parte de las reedificaciones de fachadas, aplicando siempre la misma composición, muy esquemática y funcional. Hay excepciones a esta solución-tipo clasicista y son las que presentan una fachada reedificada en estilo neomedieval (San Marcos de Corcubión, parroquial de Pontesampaio). Este estilo es el que escoge también para los templos de nueva planta: San Andrés de Lourizán, Santiago de Viascón y Santo Tomás de Caldas de Reis.

\footnotetext{
${ }^{46}$ Las Comisiones de Monumentos Históricos y Artísticos se crearon en España por R.O. De 13 de junio de 1844. Se creó una Comisión en cada provincia, dependientes de la Comisión Central. Estas instituciones tuvieron muchas dificultades de funcionamiento debido a falta de presupuesto y capacidad organizativa. ORDIERES DÍEZ, I. (1995), 46 y ss. Desde 1858 el arquitecto provincial era miembro nato de la Comisión de Monumentos de su provincia. SÁNCHEZ GARCÍA, J.A. (1997), 199.

${ }^{47}$ Concebido por su autor como complemento al informe encargado por la Comisión Central de Monumentos sobre un viaje arquitectónico a las provincias de España realizado por algunos de sus miembros en 1847 . Véase nota anterior.

${ }^{48}$ ISAC, A. (1987), 131 y ss.
} 
El neomedievalismo en estas iglesias diseñadas por Sesmero está muy simplificado, reducido a esquemas proporcionales y decorativos fácilmente repetibles, con formas geométricas simples y superficies planas que delatan su formación académica. No responde a ninguna reivindicación nacionalista ${ }^{49}$, ya que en su mayor parte se inspira en elementos que no estaban presentes en la arquitectura gallega. Tampoco responde la elección de este lenguaje a una idea racionalista de la arquitectura, como defendió Viollet-le-Duc en Francia ${ }^{50}$, sino sólo a una moda ${ }^{51}$-que provenía de Europa, donde ya se practicaba desde los años $30^{52}$ - basada en la idea de eclecticismo tipológico ${ }^{53}$, que consideraba el neorrománico y el neogótico como los estilos apropiados para las iglesias de nueva construcción ${ }^{54}$. Esta idea se refuerza

${ }^{49}$ Como sí sucedió en Cataluña y Baleares o en Castilla. Sobre el neogótico en Baleares y su vinculación con la ideología de la Renaixença veáse CANTARELLAS CAMPS, C. (1981), 151, 408-421, 510, 513. En Francia la arquitectura gótica era considerada como una arquitectura nacional. HAUTECOEUR, L. (1955), Tome VI, 285. También en Alemania y en Inglaterra fue considerada un arte nacional. Esta cuestión del nacionalismo arquitectónico fue fuente de discusiones en la Europa del siglo XIX, y es el origen del enfrentamiento que tuvo lugar en Francia en los años cuarenta entre «clásicos» y «góticos». Sobre este problema véase PATETTA, L. (1974).

${ }^{50}$ Viollet-le-Duc concebía la arquitectura gótica como un modelo racional de construcción del que debían ser asimilados los principios para regenerar la arquitectura en Francia. VIOLLET-LE-DUC, E. Texto publicado en junio de 1846 en Annales Archéologiques y reproducido en PATETTA, L. (1974), 29.

${ }^{51}$ Defendida por los arquitectos «neogóticos» que veían en la arquitectura gótica un modelo de racionalismo y una fuente de renovación de la arquitectura, frente al eclecticismo clasicista practicado por los «académicos», pero también defendida por la Iglesia, que en 1846 se pronuncia a favor de la adopción de este estilo para las iglesias nuevas en las diócesis de Francia. PATETTA, L. (1974), 7. Los neogóticos, además de considerar la arquitectura gótica como racional, pensaban que era la arquitectura cristiana por excelencia, lo que también fue objeto de fuerte polémica en la Francia de los años cuarenta ya que la Academia se oponía a esta idea tanto como a la de considerar la arquitectura gótica como un arte racional. Memoriale de L'Académie des Beaux-Arts publicado en Le Moniteur des Arts en mayo de 1846. Reproducido de PATETTA, L. (1974), 13-19.

${ }^{52}$ En Inglaterra, ya desde mediados del siglo XVIII se había hecho común construir en estilo gótico las iglesias nuevas. Sin embargo no es hasta aproximadamente 1820 cuando se despierta un verdadero interés arqueológico que luego aplicará sus descubrimientos en los proyectos de este tipo de construcciones. El origen del interés por el gótico se sitúa en Inglaterra, en el movimiento Pintoresco iniciado en la segunda mitad del XVIII. Allí se inicia en los años 20 una campaña de construcción de iglesias parroquiales «baratas» $\mathrm{o}$ «de encargo» en estilo neogótico «no arqueológico», según HITCHCOCK, H.R. (1985), 159.

${ }^{53}$ El eclecticismo tipológico consistía en la utilización de un estilo histórico diferente y determinado para cada tipología edilicia.

${ }^{54}$ Se empezó a considerar, desde los primeros decenios del siglo XIX -en Francia alrededor de Montalembert y en Inglaterra alrededor de Pugin- la arquitectura gótica como el instrumento para la restauración del verdadero catolicismo. MIGNOT, C. (1983), 58. «Au moment où la Restauration ne semblait pas seulement politique, mais religieuse, le retour au Gothique était un retour à la foi». HAUTECOEUR, L. (1955), TomeVI, 285. Véase también HITCHCOCK, H.R. (1985), 160. 
a partir del Concilio Vaticano I (1869-1870) en el que la arquitectura se entiende como símbolo de cierto rearme católico ${ }^{55}$. En España esta tendencia se afianza ${ }^{56}$ con el auge de la ideología neocatólica contemporánea al régimen de la Restauración, a partir de los años setenta ${ }^{57}$.

Tampoco aplica Sesmero criterios arqueologistas en estas obras de restauración o de nueva planta. No hay una intención de reponer elementos tal y como hubiesen sido o pudiesen haber sido en las obras de restauración aunque sí, en algún caso, una aplicación de ciertos criterios de restauración en estilo. Del mismo modo, en las obras de nueva planta no trata de reproducir modelos históricamente verdaderos, sino tan sólo de conjugar en una misma iglesia elementos diversos tomados de momentos diferentes de la historia de la arquitectura medieval. Incluso en algunas de sus obras llega a mezclar elementos de origen clasicista con elementos de inspiración medieval, llegando a aplicar, por ejemplo, sencillos óculos donde deberían aparecer rosetones. La regularidad compositiva, la simetría y la proporcionalidad equilibrada que se observa en todas sus obras neomedievales dejan entrever la utilización de métodos de composición clasicista ${ }^{58}$.

Por otra parte, los conocimientos históricos o arqueológicos sobre los edificios a restaurar o consolidar eran por lo general muy limitados. En la mayoría de los casos abordados por Sesmero como arquitecto diocesano se trataba de pequeños y frecuentemente muy humildes templos parroquiales que no se podían datar fácilmente en ningún período cronológico concreto sino que se iban haciendo y rehaciendo a lo largo del tiempo sin que quedara testimonio de los cambios. A esto hay que añadir la limitada formación de los arquitectos en materia de historia de los estilos arquitectónicos en un momento en que todavía la historiografía arquitectónica en España y en Galicia, se estaba creando. Además, los edificios a restaurar por los arquitectos diocesanos eran siempre edificios vivos (en uso), lo que añadía nuevos problemas y matices a la aplicación de las teorías sobre restauración en boga, que la mayoría de las veces estaban formuladas para edificios cuyo valor

\footnotetext{
${ }^{55}$ NAVASCUÉS PALACIO, P. (1993), 291.

${ }^{56}$ HERNANDO, J. (1989), 214.

${ }^{57}$ La constitución de 1876 restaura el catolicismo como religión del Estado español, por oposición a la libertad de cultos de la constitución anterior de 1869. DARDÉ, C. (1996), 14.

${ }^{58}$ Sobre la supervivencia a lo largo del siglo XIX de métodos de composición academicista véase VAN ZANTEN, D.: «Architectural composition at the Ecole des Beaux-Arts. From Charles Percier to Charles Garnier», en DREXLER, A. (ed.) (1977). Un ejemplo en el que se ve la aplicación de la composición académica a un proyecto «neomedieval» es la iglesia diseñada por Gaudet en sus planos para un Hospicio en los Alpes, de 1864 (p. 256). Véase también Rykwert, J.: «The Ecole des Beaux-Arts and the classical tradition», en MIDDLETON, R. (ed.) (1984), 9-17.
} 
artístico e histórico era mucho mayor que el de los sencillos templos parroquiales, objeto preferente de la atención de las Juntas de Construcción y Reparación, que buscaban ante todo soluciones funcionales.

\section{DIÓCESIS DE TUI (1882-1886)}

Como arquitecto diocesano de Tui, Sesmero sucede en el cargo a Justino Flórez Llamas. Entonces Sesmero era municipal de Vigo, por lo que cumplía el requisito de residir en la circunscripción de la diócesis, necesario para ser nombrado arquitecto diocesano ${ }^{59}$.

En Tui, la primera obra en la que interviene será la construcción del nuevo templo de San Miguel de Ponteareas, diseñado por su antecesor Justino Flórez en 1880 en sustitución del anterior templo de finales del siglo XVIII, que resultaba de reducidas dimensiones ${ }^{60}$. Flórez concibió uno nuevo muy suntuoso, en estilo neogótico (Figura 1). Dadas las crónicas limitaciones presupuestarias de la Junta de Construcción y Reparación de edificios eclesiásticos de la diócesis de Tui, limitaciones que eran comunes a las otras diócesis gallegas ${ }^{61}$, el templo no se llegó a llevar a cabo en su totalidad con absoluta fidelidad al proyecto. Ya Justino Flórez había contemplado la posibilidad de que la decoración pudiese suprimirse en parte o incluso en su totalidad en caso de necesidad. A Domingo R. Sesmero corresponderá la dirección de las obras desde 1882 a 1886 y la reducción de la idea inicial a una realidad mucho más desornamentada de lo en principio imaginado, aunque estructuralmente el edificio sí responde al pensamiento original (Figura 2).

Flórez dirige las obras, iniciadas en marzo de 1881, hasta mayo de 1882, momento en que este arquitecto abandona Galicia, siendo sustituido en la diócesis por Domingo R. Sesmero. Éste asume la dirección de la construcción, que se prolonga desde que toma posesión del cargo, durante el verano de 1882, hasta que lo abandona cuatro años después, y aún la iglesia no estaba terminada en esa fecha. Sesmero

\footnotetext{
${ }^{59}$ Real Decreto de 13 de Agosto de 1876 dictando reglas á que han de someterse las obras de construcción y reparación de los templos catedrales, colegiales y parroquiales, palacios episcopales, seminarios conciliares, e iglesias y casas de religiosos y religiosas. Creación de Juntas diocesanas: Arquitectos, etc. MARTÍNEZ ALCUBILLA, M. (1893), 503-504.

${ }^{60}$ A.H.D.T-V. Parroquia de San Miguel de Ponteareas. Expediente de construcción de la iglesia parroquial. 1878-1892.

${ }^{61}$ Véase el estudio que hace sobre el trabajo de Faustino Domínguez Domínguez en la diócesis de Santiago SÁNCHEZ GARCÍA, J.A. (1997), 124 y ss. Ver también nota 10.
} 
en principio se limita a dirigir las obras según el proyecto de Flórez, aportando al contratista planos de ejecución con la forma y dimensiones de puertas, ventanas, cornisas, arcos, estribos, etc. Por R.O. de 3 noviembre de 1883 se pide al arquitecto diocesano «se verifiquen las obras introduciendo la mayor economía posible, suprimiendo toda decoración que no sea de absoluta necesidad». Sesmero opina, en escrito posterior, que ésta le parece una «acertadísima disposición» y que por ello se ha limitado la sillería exterior a estribos y arcos de ventanas -exceptuando la fachada-. Añade también que se ha modificado «la armadura, que llevará teja del país como todos los templos de Galicia y no de Marsella». La obra se paraliza en 1883 debido a problemas surgidos con el contratista. El 30 de Junio de 1885 Sesmero aporta un presupuesto adicional con las obras que faltaba realizar en ese momento y que incluía planos de la aguja de la torre -Sesmero propone que sea construida de piedra y no de madera cubierta de pizarra como se contemplaba en el proyecto original-, la construcción de las bóvedas -de ladrillo y no de madera, altares y púlpito de madera pintada y dorada en algunas de sus partes y en el mismo estilo del edificio-. Otras intervenciones contempladas en el presupuesto adicional eran la elevación del pavimento, embaldosado de piedra de grano fino, bajorrelieve con el santo titular del templo sobre el dintel de la puerta, además de diversas obras de albañilería, carpintería y colocación de las vidrieras, que se proponen sin color por ser más baratas y no en colores como se decía en el proyecto original de Justino Flórez. Estas obras no saldrán a subasta hasta 1888 y se realizarán ya bajo la dirección del nuevo arquitecto diocesano que sucede a Sesmero, Manuel Felipe Quintana.

La intervención de Sesmero, a la vista de la fachada actual, consistió en suprimir todos los mascarones decorativos que se alojaban en el interior de una serie de pequeñas arcuaciones situadas bajo la cornisa. Elimina también esas arcuaciones. Sustituye el rosetón central de la fachada situado en la calle principal por un sencillo óculo y los pequeños rosetones de las calles laterales por otros dos óculos más reducidos. También suprime la molduración goticista de las ventanas. Desaparece asimismo la decoración escultórica de los estribos frontales que limitan la fachada. Pero el cambio más significativo es la sustitución de la torre propuesta por Flórez por otra más sencilla, que presenta un carácter menos goticista, y que pudiera remitir a modelos románicos franceses tomados del Dictionnaire de Viollet-le-Duc ${ }^{62}$.

${ }^{62}$ Véase la torre de la iglesia de Poissy, de los primeros años del siglo XII, reproducida en VIOLLET-LE-DUC, E. (1858-68), Tomo III, 322, y también la entrada Flèches de pierre, en el tomo V, 429. Sobre la influencia de Viollet-le-Duc y sus obras en España véase GONZÁLEZVARAS IBÁÑEZ, I. (1999), 175 y ss. ORDIERES DÍEZ, I. (1995), 126. 


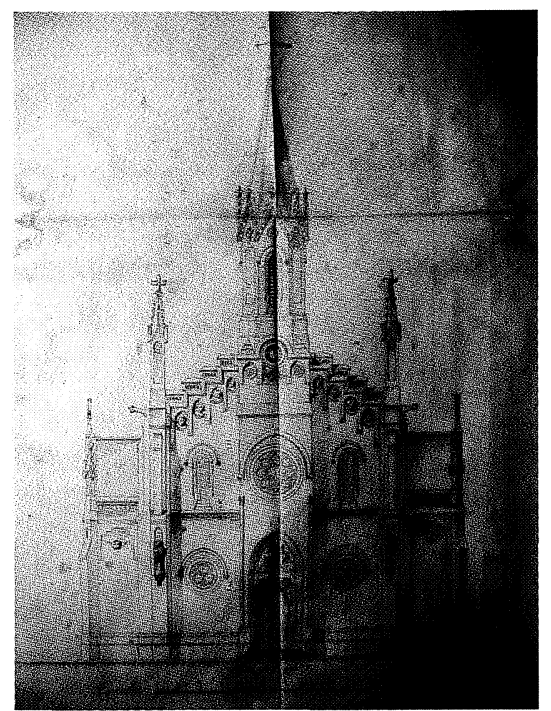

Figura 1.- Proyecto de Justino Flórez Llamas para San Miguel de Ponteareas.

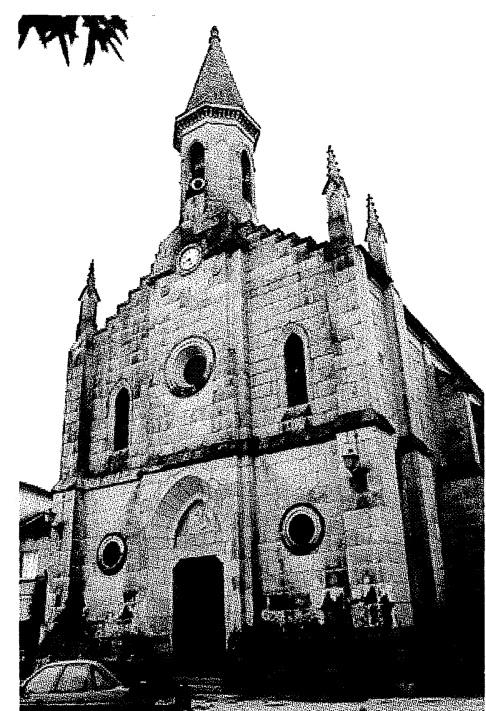

Figura 2.- Fachada actual de San Miguel de Ponteareas.

Otras reparaciones, de menor importancia, en las que intervino Sesmero en la diócesis de Tui fueron:

- Dirección y supervisión de las obras de consolidación y reparación de la Iglesia parroquial de San Andrés de Cedeira (Redondela), según proyecto de Justino Flórez Llamas de 1881. Las obras se llevan a cabo entre 1881 y 1883.

- San Salvador de Cristiñade (Ponteareas), obras de reparación y reforma según planos de Justino Flórez presentados en Agosto de 1881. Sesmero se limita a reconocer las obras y dar la recepción provisional en diciembre de1882.

- Convento de la Concepción de Tui, obras de reparación a causa de falta de reparaciones ordinarias, según presupuesto de Justino Flórez. Sesmero aportará un presupuesto adicional en 1883 para reparar unas goteras en los dormitorios de las religiosas.

- Templo parroquial de San Xoan de Angudes (Crecente), Sesmero reconoce obras de reparación realizadas según proyecto de Justino Flórez de 1878, recibiéndolas provisionalmente en julio de 1884 . 
- Santa María de Areas (Ponteareas), en noviembre de 1883, Sesmero visita el templo y emite un informe sobre el estado de un elemento algo deteriorado de la estructura.

- O Salvador de Leirado (Salvaterra de Miño), Sesmero forma en noviembre de 1882 un presupuesto adicional de 3.000 pts. al presupuesto inicial de Justino Flórez de 1879, por haberse declarado en ruina lo que quedaba del templo una vez realizadas las obras de reparación y reforma del proyecto de Flórez.

- San Mamed de Petelos (Mos), Sesmero realiza reconocimiento del templo al que califica de pobre y en mal estado de solidez, añadiendo que la reparación no puede realizarse con las escasas 4.500 pts. concedidas por R.O.

\section{DIÓCESIS DE SANTIAGO. (1884-1897)}

El trabajo realizado al servicio de la Junta de construcción y reparación de templos de la diócesis de Santiago será más importante que el realizado en Tui, explicable por una más prolongada permanencia en el cargo (1884-1897), llegando a proyectar tres iglesias de nueva planta además numerosas reedificaciones de fachadas, ampliaciones, reparaciones y consolidaciones interiores de pequeños templos parroquiales.

La Junta Diocesana de Santiago se había creado en 1861 (Real Decreto del 4 de octubre de 1861). Hasta 1876 en que se crea la figura de Arquitecto Diocesano, se encargaba de los proyectos el Arquitecto Provincial. Una vez creada la plaza, ésta será ocupada por Antonio Bermejo y Arteaga, que será auxiliado por Faustino Domínguez Domínguez desde 1877. Domínguez, como Arquitecto Provincial ya se había ocupado de obras para la diócesis desde 1859. En 1883 Domínguez es sustituido interinamente por su hijo Faustino Domínguez Coumes-Gay y en 1884 por Domingo Rodríguez Sesmero ${ }^{63}$.

De nueva planta realiza Sesmero los templos de San Andrés de Lourizán (Pontevedra, 1886-1888), Santo Tomás de Caldas de Reis (1890-1893) y Santiago de Viascón (Cotobade, 1886-1893). Las tres tienen en común el ser iglesias con planta de una sola nave, construidas de piedra (granito) y en estilo neomedieval. Las de Lourizán y Caldas son las de mayores dimensiones por prestar servicio en poblaciones más populosas.

${ }^{63}$ SÁNCHEZ GARCÍA, J.A. (1997), 124, 125. 
Antes de comentar estas tres iglesias, es preciso referirse a la obra de construcción de nueva fachada de San Marcos de Corcubión, realizada según proyecto de Sesmero, ya que es en ella donde por primera vez aplica este arquitecto el estilo neogótico ${ }^{64}$, según un esquema que luego veremos repetido casi con exactitud en la fachada de San Andrés de Lourizán.

La reedificación de la fachada de la iglesia de San Marcos de Corcubión ${ }^{65}$, fue proyectada en 1885 y realizada entre 1892 y 1894. Esta iglesia de origen románico se había terminado en el siglo XV, produciéndose en ella posteriores adiciones ${ }^{66}$. Durante el siglo XIX sufrió desperfectos por causa de rayos, que destruyeron parte de su torre en 1868 y la totalidad de la fachada en 1885. En la memoria explicativa Sesmero describe el templo y el estado en que se hallaba en el momento de redactar su proyecto para la nueva fachada: «El templo parroquial de Corcubión es uno de los mejores que tiene la Diócesis en todo su litoral, de Arquitectura Gótica de lo más primitivo, compuesto de una anchurosa nave central con arcos ojivales de pequeñas proporciones en sus arranques, dos capillas más modernas y de estilo Románico a cada lado y su presbiterio de mucha antigüedad aun formando un conjunto agradable. Este edificio se halla emplazado en la parte más alta de la población y en el ángulo que forma la división entre la ría y la costa de Finisterre terrible siempre por sus grandes huracanes y tormentas que llenan de espanto a aquellos moradores habiendo ocurrido ya en el año 1868 que una chispa eléctrica destruyera parte de la hermosa torre construida en la época de la fundación del templo, y ya sea por negligencia o falta de recursos, no se tomaron precauciones para evitar esta clase de siniestros colocando convenientemente uno o dos pararrayos; lo cierto es que el 19 de Marzo del corriente año, en ocasión en que la mayoría de los feligreses celebraban el día de San José en el acto de oír la Misa Mayor una descarga eléctrica de las mayores conocidas por los habitantes de la comarca destruyó hasta los cimientos los restos de la derruida torre y arrasó toda la fachada ocasionando tres muertos y cincuenta y ocho heridos graves siendo providencial el que su instantáneo hundimiento se haya verificado hacia el exte-

\footnotetext{
${ }^{64}$ Con la única experiencia previa de la intervención en la construcción del templo de San Miguel de Ponteareas según proyecto de Flórez Llamas, comentado más arriba.

${ }^{65}$ Erróneamente atribuida a Alejandro Rodríguez-Sesmero, al que confunde con Domingo Rodríguez Sesmero, por LÓPEZ VÁZQUEZ, J.M. (1995), 153. Está correctamente atribuida a Domingo en FERNÁNDEZ FERNÁNDEZ, X. (1995) vol. I, 273 y ss.

${ }^{66}$ CAAMAÑO MARTÍNEZ, J.Ma (1962), 121, 123; CARRÉ ALDAO, E. (1928-1935), 218.
} 
rior del edificio, pues de lo contrario hubiera ocasionado dobles víctimas y la destrucción completa del edificio». ${ }^{67}$

Sesmero proyecta una nueva fachada que se antepone al plano de fachada de la antigua, de la que se conserva el arco de la puerta. Entre la nueva fachada y la antigua queda un espacio que hace de pórtico, a los lados del cual, y del mismo modo que repetirá en Lourizán y en Caldas, dispone un baptisterio y una escalera de acceso al coro y torre. La idea de conservar el arco primitivo en el interior de esta nueva fachada puede responder a la valoración que el arquitecto hace del edifício, que le parece uno de los mejores de la diócesis. Aunque también es claro que responde a motivos funcionales de necesidad de ampliación de la iglesia.

La nueva fachada, toda de sillería fina de granito, responde a un esquema compositivo regular en torno a un eje central de simetría (Figura 3). Está dividida en tres calles, que se separan por medio de dos contrafuertes a los lados de la calle central. Se colocan otros dos contrafuertes en las esquinas de la fachada. Estos estribos tendrían una función más bien compositiva, e incluso decorativa, que funcional y no responden tampoco a una necesidad de armonizar con el resto del edificio, ya que éste no tiene contrafuertes en el resto de sus muros. Se trataría tan sólo de evocar elementos medievales antes que de responder a necesidades constructivas. Una torre de un solo cuerpo y de base cuadrada flanqueada por cuatro pináculos se coloca sobre el centro de la fachada y se corona con una aguja o chapitel de sillería de base octogonal, flanqueada a su vez por otros cuatro pináculos iguales a los anteriores. En el lugar que hoy ocupa el reloj había proyectado Sesmero un pequeño rosetón, que por sus dimensiones y aspecto desornamentado apenas puede denominarse como tal sino que sería más bien un simple óculo.

La composición de la fachada es sencilla y de proporciones un tanto achaparradas, tal vez para adaptarse a las dimensiones del resto del edificio. Se advierte una falta de adecuación entre el estilo escogido para la fachada-que parece que requeri-

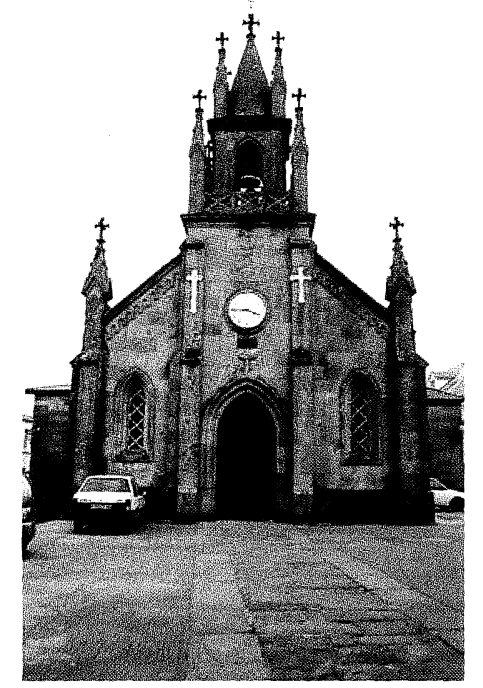

Figura 3.- Fachada actual de San Marcos de Corcubión.

${ }^{67}$ A.H.D.S. Fondo general. Templos. C-1.255. Expediente de reparación de la iglesia parroquial de San Marcos de Corcubión. 1885-1896.

Cuadernos de Estudios Gallegos, Tomo LII, Fascículo 118, Santiago 2005. (Págs. 305 - 345) 
ría unas proporciones más alargadas-y el resto de la construcción, en la que domina lo horizontal sobre lo vertical. Esto demuestra que Sesmero no está aplicando conocimientos arqueológicos en su proyecto, sino simples elementos descontextualizados que remiten a una imagen vagamente medieval, gótica sí, pero de un modo genérico, donde los elementos utilizados pueden provenir de libros manejados por el arquitecto, pero con escasa relación con lo que pudo haber sido la fachada original, ya que no encontramos en Galicia ningún templo gótico con semejante composición en su fachada. Algunos de los elementos utilizados, como la torre o los pináculos, podrían tener en el Dictionnaire de Viollet-le-Duc algunos de sus modelos ${ }^{68}$.

Sobre este diseño el arquitecto hace el siguiente comentario en la memoria explicativa del proyecto: "El estudio de fachada aparecerá a primera vista como costoso y de cierto lujo, mas vistas sus reducidísimas proporciones y teniendo en cuenta que en el país la sillería de granito es el material más abundante y más barato que existe, asi como los hijos del país se dedican con preferencia a labrantes del granito, son origen que se lleven a cabo construcciones de sillería muy económicas. Se ha escogido y preferido el orden gótico en el estudio de la fachada y reduciéndolo a su más mínima expresión por estar en carácter con el orden de arquitectura a que pertenece el edificio, su construcción es toda de granito fino y liso. El basamento de la torre afecta la forma de un rectángulo de cuatro metros de lado, creando una subida al coro y un batisterio de que carecía el templo (...). Para evitar la repetición de los siniestros anteriores se le ha dado a la torre la menor altura posible, al primer cuerpo diez metros y al segundo incluyendo la aguja ocho metros finalizando con un para-rayo cuya atracción domina todo el radio del edificio (...)» ${ }^{69}$

Una vez formado el proyecto de reedificación, se remite éste al arquitecto provincial, Faustino Domínguez Domínguez para que dé su aprobación, tal y como ordenaba el R.D. de 13 Agosto de 1876 relativo a construcción y reparación de templos cuando las obras excediesen la cantidad de 5.000 ptas.. Domínguez aprueba el proyecto diciendo: "Califica (Sesmero) la iglesia de Corcubión como uno de los mejores templos que tiene el Arzobispado en todo el litoral. Es de arquitectura gótica, pero en sentir del arquitecto provincial no pertenece a la época florida de este estilo, aunque el autor ya dice en la memoria que es de un estilo gótico del

\footnotetext{
${ }^{68}$ Véanse, por ejemplo, las entradas Clocher y Pinacle en VIOLLET-LE-DUC, E. (1864-1868), tomo III, 391 y tomo VII, 176-187, donde se reproducen elementos similares.

${ }^{69}$ A.H.D.S. Fondo general. Templos. C-1.255. Expediente de reparación de la iglesia parroquial de San Marcos de Corcubión. 1885-1896.
} 
más primitivo (...). Los planos de fachada que son del estilo gótico que queda indicado están bien dibujados y ofrecen un aspecto bastante agradable». ${ }^{70}$

El estado había concedido la cantidad de 20.000 pesetas para la obra, Sesmero da en principio un presupuesto de 24.000 pesetas, pero posteriormente se le solicita uno nuevo más reducido, presentándolo el 22 de setiembre de 1892, de 20.000 pesetas. Las obras comienzan en noviembre de ese año, se reciben provisionalmente en 1894 y definitivamente en febrero del año siguiente.

San Andrés de Lourizán (Pontevedra), situada en el lugar de Placeres ${ }^{71}$, muy próximo a la ciudad de Pontevedra, fue construida a partir de 1887 según proyecto presentado ante la Junta diocesana de Santiago el 30 de junio de 1886 por Domingo Rodríguez Sesmero ${ }^{72}$.

Existe en el expediente un presupuesto aproximado previo al proyecto, firmado por el maestro de obras e hijo de Domingo, Alejandro Rodríguez-Sesmero González. Este presupuesto está datado en enero de 1886 y ascendía a 76.000 pts. En este presupuesto previo aportado por Alejandro R. Sesmero - quien era por aquellas fechas arquitecto municipal de Pontevedra- ya aparecen detalladas algunas de las características de lo que será el nuevo templo, como es la idea de colocar una sola torre central en la fachada. Esto plantea la cuestión de la posibilidad de la intervención del hijo del arquitecto diocesano en la concepción de este edificio. Aunque, por otra parte, la composición de la fachada remite directamente a la de San Marcos de Corcubión, por lo que si en Lourizán hubo una intervención de Alejandro Rodríguez-Sesmero González esto implicaría que también la hubo en Corcubión.

Las obras de construcción son autorizadas por R.O. de 12 de octubre de 1886 para ser llevadas a cabo según el proyecto de Domingo Rodríguez Sesmero, que había obtenido previamente el visto bueno del arquitecto provincial Antonio Crespo. El 30 de mayo de 1888 Domingo R. Sesmero presenta un presupuesto adicional para la construcción del cerramiento del atrio. En noviembre de 1888 todas las obras estaban concluidas.

\footnotetext{
${ }^{70}$ Ibídem.

${ }^{71}$ El templo fue levantado en terrenos en parte propiedad del político Eugenio Montero Ríos, quien intervino activamente en las gestiones necesarias para la obtención de fondos ante el Ministerio de Gracia y Justicia, cartera de la que había sido titular en varias ocasiones, lo que contribuyó a que el edificio fuera erigido en un plazo menor que otros templos de nueva planta proyectados en esa época en la diócesis. FERNÁNDEZ FERNÁNDEZ, X. (1995), 276 y ss.

${ }^{72}$ A.H.D.S. Fondo general. Templos. C-1253. Expediente de construcción de la iglesia parroquial de San Andrés de Lourizán.
} 


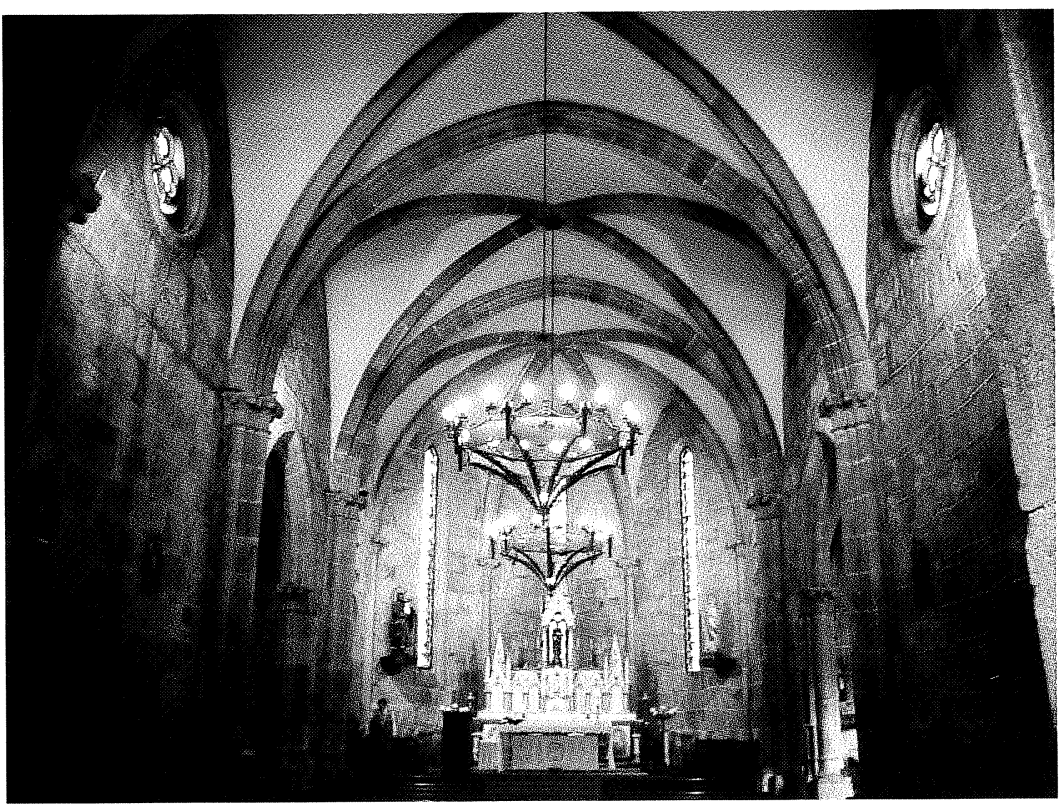

Figura 4.- San Andrés de Lourizán. Vista de la nave.

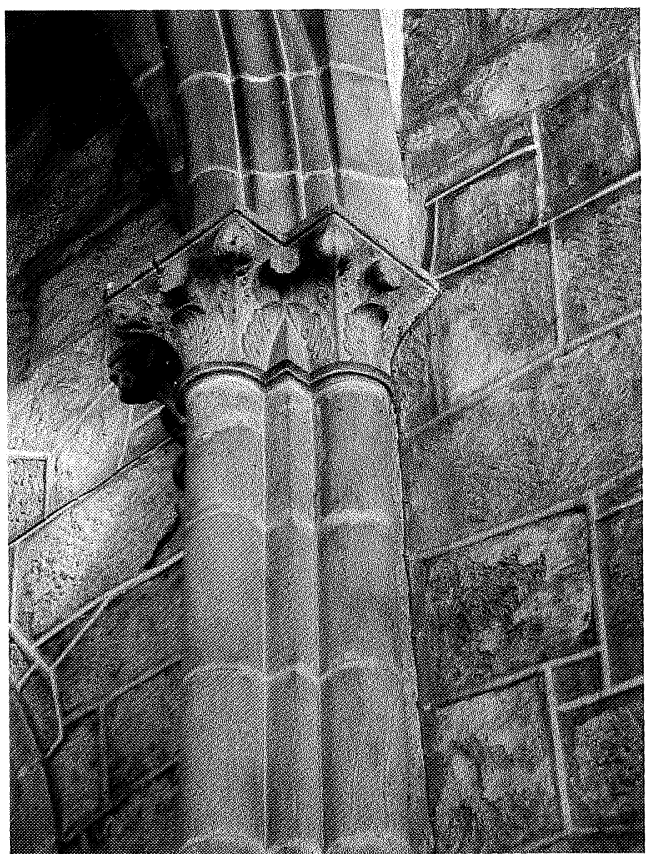

Figura 5.- San Andrés de Lourizán. Capiteles de la nave.

Cuadernos de Estudios Gallegos, Tomo LII, Fascículo 118, Santiago 2005. (Págs. 305 - 345) 
La iglesia es de una sola nave con una capilla a cada lado del crucero conformando una planta de cruz latina rematada por una cabecera poligonal, flanqueada ésta simétricamente por sendas estancias adyacentes destinadas a sacristías. A los pies hay un espacio que sirve de vestíbulo, a ambos lados del cual se sitúan el baptisterio y la caja de escaleras de acceso a coro y torre. La nave se divide en tres tramos separados por arcos fajones apuntados de piedra y cubiertos por bóvedas de crucería (Figura 4). Los muros son de mampostería concertada y el alzado se organiza por medio de grupos de tres semicolumnas acodilladas, de sillería, de mayor diámetro la central, rematadas en capiteles neogóticos con motivos vegetales que sirven de apoyo a los arcos fajones y cruceros (Figura 5). Se accede a cada capilla lateral por medio de un arco de ingreso apuntado con varias molduras, arco que descansa sobre columnas con capiteles tallados iguales a las de la nave. Las capillas se cubren con bóveda de crucería. La nave se ilumina por medio de cuatro pequeños rosetones, también de piedra, con tracería polilobulada, abiertos en los muros laterales. En la cabecera, de cinco lados, se abren tres largas y estrechas ventanas verticales situadas simétricamente respecto al eje longitudinal de la iglesia -la central sobre el eje- y cerradas por medio de vidrieras coloreadas. El mobiliario fue también diseñado por Domingo R. Sesmero y todavía sigue en uso. Todos los muebles presentan el mismo estilo neogótico del templo: en el ábside el altar mayor, en las capillas laterales sendos altares iguales y en la nave los confesionarios (Figura 6). El pavimento de todo el templo es de cemento Portland y es el único elemento en el que se recurre a materiales modernos. La cubierta se proyectó de teja, tal y como la vemos actualmente.

Exteriormente los muros de mampostería concertada se levantan sobre un zócalo de sillería y están reforzados por contrafuertes también de sillería lisa. La fachada se concibe simétricamente con respecto a un eje vertical (Figura 7). Dividida en tres calles separadas por estribos, la calle central coincide con el cuerpo de la torre y se remata por el piso de las campanas y la aguja. En cada una de las tres calles de la fachada se abre un vano alargado similar a los del ábside, pero cerrados con tornavoces, el de la calle central algo más reducido en su altura que los de las calles laterales. Sobre el vano de la calle central se abre también un rosetón igual a los que iluminan la nave. Bajo la cornisa inclinada de las calles laterales se sitúa una decoración de arquillos ciegos. Los extremos laterales de la fachada se refuerzan con contrafuertes rematados en sendos pináculos decorados iguales a los vistos en San Marcos de Corcubión. Estos pináculos podrían haber sido copiados de modelos reproducidos en el Dictionnaire de Viollet-le-Duc (Figura 8) ${ }^{73}$. Estos pi-

${ }^{73}$ Véase la entrada Pinacle, en VIOLLET-LE-DUC, E. (1858-1868), tomo VII, 180. 


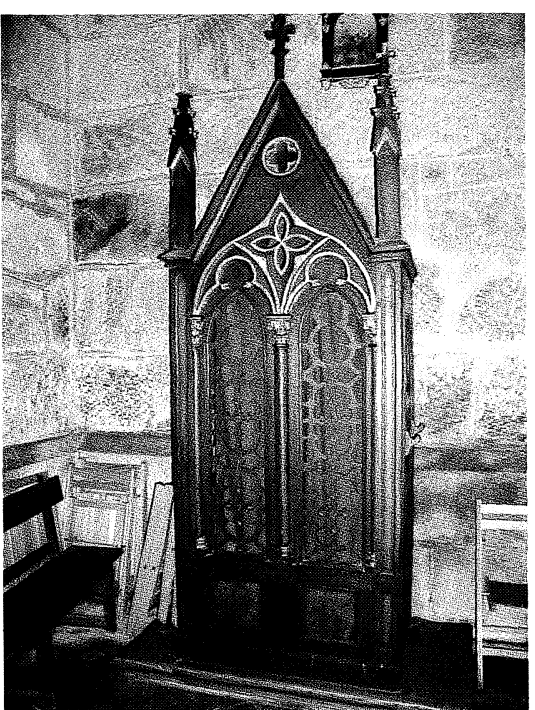

Figura 6.- San Andrés de Lourizán. Confesionario.

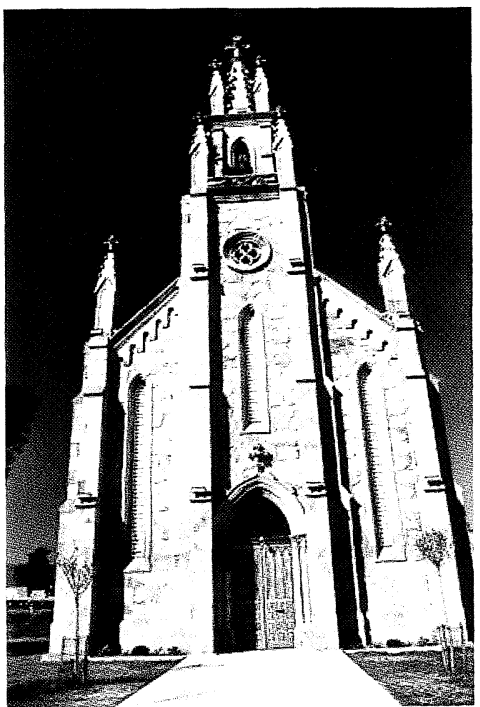

Figura 7.- San Andrés de Lourizán. Fachada principal.

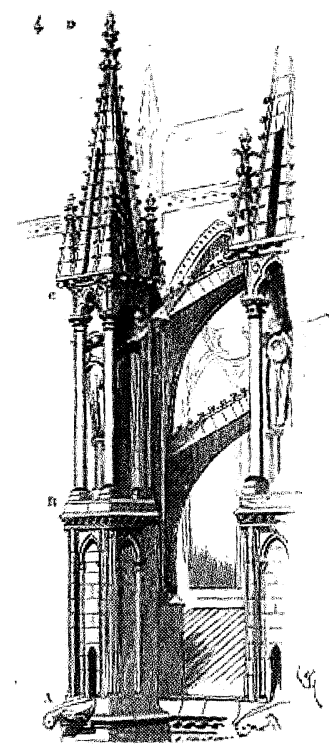

Figura 8.- Pináculo gótico. Lámina del Dictionnaire... de Viollet-le-Duc. 
náculos se repiten en los cuatro ángulos del cuerpo cuadrado de las campanas y se vuelven a repetir flanqueando por sus cuatro lados la aguja de la torre. Todos los pináculos, así como la aguja están coronados cada uno por una cruz florenzada ${ }^{74}$. En la fachada la sillería fina y lisa se limita a los estribos, cornisas y decoración de arquillos ciegos, cuerpo de las campanas, aguja y pináculos, molduras y decoración de vanos y columnas de la puerta, mientras que el muro es de mampostería concertada. El acceso al templo se realiza a través de un arco apuntado, situado en el eje de la fachada, con varias molduras, la exterior en forma de arco conopial decorado en el trasdós con frondas y rematado en el vértice por una cruz similar a la que remata la aguja de la torre y los diversos pináculos decorativos que ornamentan la fachada. Este arco de ingreso está sostenido por pares de columnas entregadas y sobre plintos.

Es evidente la similitud compositiva y decorativa entre esta fachada y la de San Marcos de Corcubión, lo que demuestra la tendencia de Sesmero a repetir sencillas fórmulas y recetas a la hora de proyectar sus obras religiosas. Aquí sin embargo las proporciones son más alargadas, lo que se explica por la libertad que tenía el arquitecto al proyectar una iglesia de nueva planta, no teniendo que adaptarse a unas preexistencias como ocurría en Corcubión. También es evidente el eclecticismo decorativo, ya que se están mezclando elementos tomados de momentos distintos de la historia de la arquitectura, como son los arquillos ciegos de origen románico, el arco conopial -del siglo XVI- de la portada, que se conjugan con pináculos típicos de la arquitectura gótica francesa del siglo XIII, o los contrafuertes de la fachada, que pueden pretender recordar fachadas cistercienses ${ }^{75}$ y todo conviviendo con reminiscencias clasicistas como pueden ser los pequeños rosetones, que más bien serían óculos. Otros elementos de la iglesia, como las ventanas de la cabecera o los capiteles de las semicolumnas de nave y capillas, podrían ser evocaciones de elementos góticos vistos por el arquitecto en las iglesias de las órdenes mendicantes de la cercana ciudad de Pontevedra.

La iglesia está rodeada de un amplio espacio que en su frente actúa de atrio, cerrado por medio de un muro de mampostería con coronación de sillería y una puerta de hierro forjado en su centro como único acceso.

\footnotetext{
${ }^{74}$ Esta cruz es muy similar al florón gótico francés reproducido por Viollet-le-Duc. VIOLLETLE-DUC, E. (1858-1868), entrada Fleuron, Tomo V, 482; MEYER, F.S. (1965), 224.

${ }^{75}$ Véase AZCÁRATE, J.M. (1996), 44. En Galicia ejemplos de fachada cisterciense con contrafuertes pueden ser la de Santa María de San Clodio (Ourense) o la de Santa María de Meira (Lugo).
} 


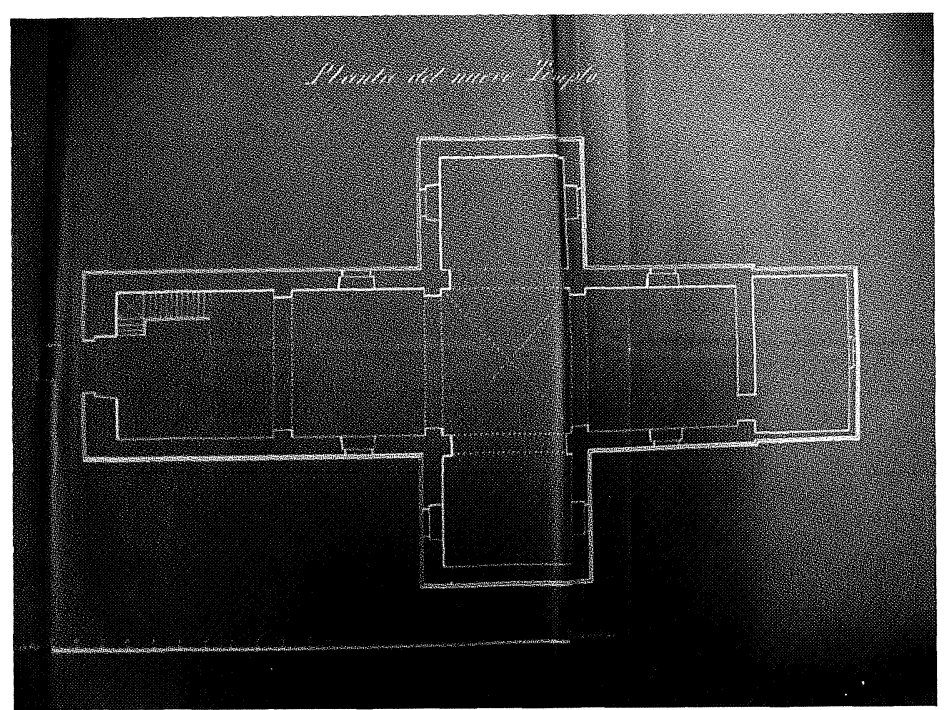

Figura 9.- Planta del proyecto de 1886 para Santiago de Viascón.

La oscuridad en el interior del templo de Lourizán, debida a sus escasos y pequeños vanos es una característica que contradice los principios estructurales de la arquitectura gótica, que tendió a hacer desaparecer el muro, sustituyéndolo por cerramientos de vidrio. Pero habría que tener en cuenta que en Galicia el gótico no produjo templos demasiado luminosos sino que debido al peso de la tradición románica en las iglesias góticas gallegas predominó siempre el muro sobre el hueco ${ }^{76}$.

La iglesia de Santiago de Viascón (Cotobade) se reedificó por completo, partiendo de una nueva planta. Existe en el expediente un proyecto datado en 1886 firmado por Sesmero ${ }^{77}$. Pero el templo actual, que fue construido entre 1891 y 1893 no responde a esa idea inicial. Lo proyectado en principio según ese primer diseño respondía a un sencillo y funcional esquema-tipo clasicista. Sin embargo, este proyecto se abandonó a favor de una realización con soluciones neomedievales en la cubrición de los tramos de la nave, transepto y presbiterio con bóvedas de crucería.

En el proyecto citado de 1886 se proponía una planta de cruz latina con dos tramos en la nave, capillas en los brazos del transepto y cabecera rectangular a la que se adosaba una estancia para sacristía al final del eje longitudinal (Figura 9).

${ }^{76}$ SORALUCE BLOND, J.R. (1986), 7.

${ }^{77}$ A.H.D.S. Fondo general. Templos. C-1247. Expediente de reconstrucción del templo parroquial de Santiago de Viascón. 1886-1892. 
Según el alzado lateral de ese primer proyecto nave y presbiterio tendrían la misma altura, cubriéndose con un mismo tejado. En los muros lisos se abren sencillas ventanas rectangulares. La fachada se concibe según una solución-tipo repetida en otros proyectos de Sesmero. Consistente en un solo cuerpo y completamente plana, se abren en el centro la puerta principal de acceso a la iglesia, de forma rectangular, con una sencilla moldura de escaso resalte que se une al zócalo. Sobre esta puerta se abre un vano semicircular, recercado por una moldura del mismo tipo. Sobre la cubierta a dos aguas se sitúa en el centro una sencilla espadaña rematada en frontón y coronada con una bola. Dos sencillas volutas unen este cuerpo de campanas con sendas bolas decorativas de remate en los ángulos del tejado (Figura 10). Este proyecto, que buscaba la mayor economía y simplicidad posibles, sufrió considerables modificaciones a la hora de llevarse a cabo, con el resultado final de un templo que sólo se parece al inicialmente proyectado en la planta, si bien también ésta sufre modificaciones. El templo proyectado en 1886 era muy modesto, tanto en diseño como en materiales, mientras que lo realizado resultó más complejo de formas y más rico materialmente, ya que las bóvedas, inicialmente proyectadas tabicadas, se realizan de sillería ${ }^{78}$. También los muros exteriores son de sillares bien labrados, frente a la idea inicial de levantarlos de mampostería.

Puede que haya habido un segundo proyecto, quizá anónimo, hoy perdido, en el que se hubiesen recogido todas estas modificaciones, que no eran pocas. Sin embargo la documentación conservada no permite asegurarlo, ya que todo el proyecto aparece dirigido por Sesmero y él mismo presenta un escrito en el que da cuenta de los cambios una vez fueron realizados. Relativo a estos cambios sólo se conserva en el expediente un plano, también de Sesmero, datado en 1890 y que representa una fachada totalmente diferente de la proyectada en 1886. Sin embargo, la fachada finalmente construida tampoco concuerda exactamente con la representada en este segundo plano sino que se ha añadido un piso más a la torre. (Figura 11).

La planta del templo construido sigue siendo de cruz latina, con dos tramos en la nave, transepto consistente en dos capillas y cabecera rectangular, pero la estancia destinada a sacristía adosada a la cabecera ha sido suprimida al tiempo que aparecen dos estancias cuadradas flanqueando simétricamente el presbiterio. Tanto los dos tramos de la nave, como las capillas del transepto, como el presbiterio

\footnotetext{
${ }^{78}$ Este cambio pudo deberse a la abundancia de granito en la zona y al hecho de ser Cotobade una zona tradicionalmente habitada por canteros. Sobre canteros en la provincia de Pontevedra, véase GARRIDO RODRÍGUEZ, X. (2000), 51.
} 


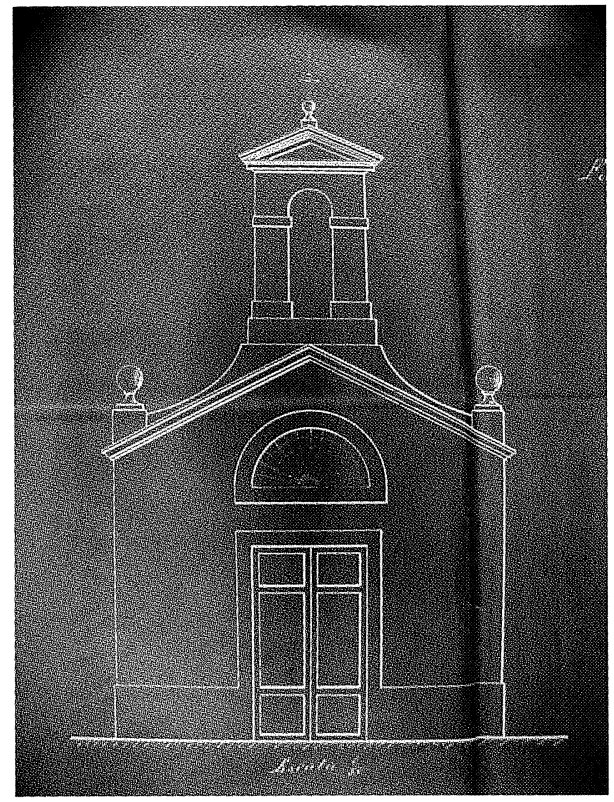

Figura 10.- Fachada del proyecto de 1886 para Santiago de Viascón.

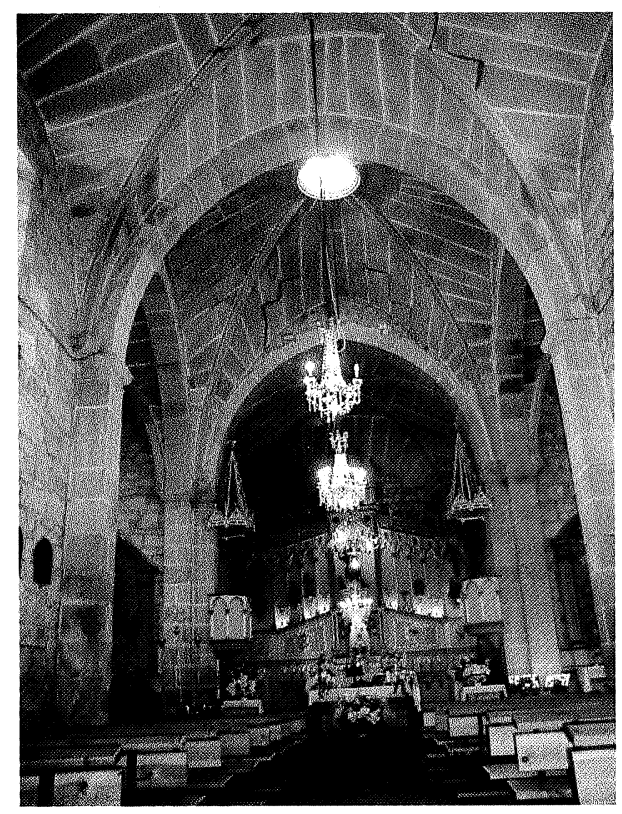

Figura 12.- Santiago de Viascón. Vista de la nave.

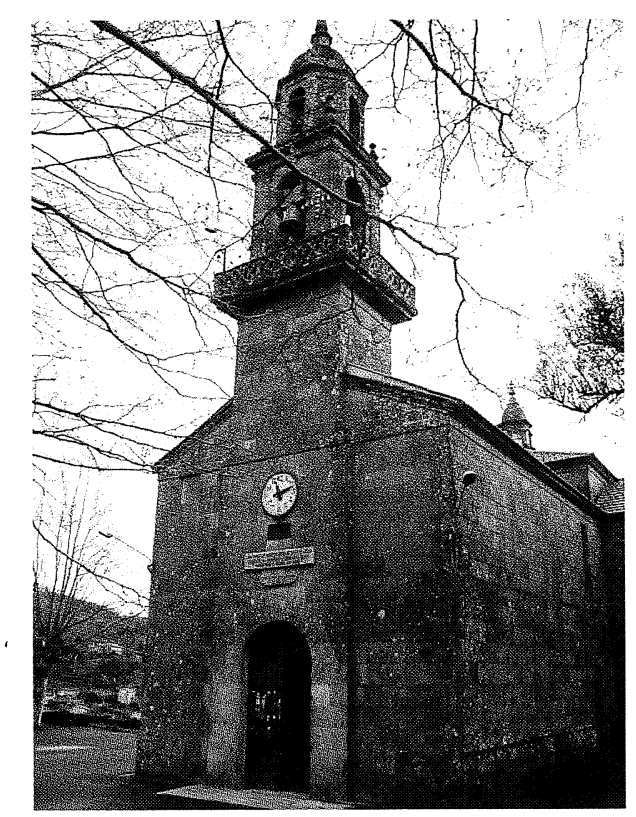

Figura 11.- Fachada actual de Santiago de Viascón.

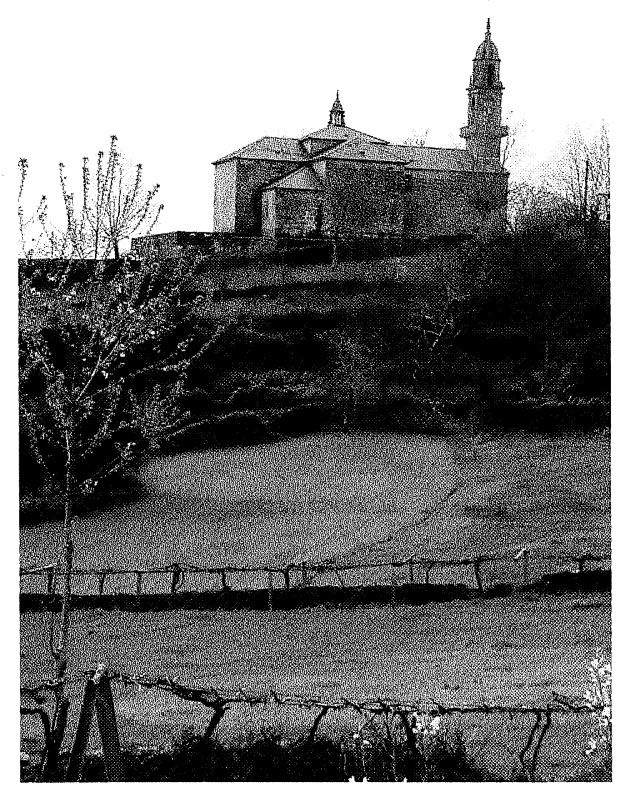

Figura 13.- Santiago de Viascón.

Cuadernos de Estudios Gallegos, Tomo LII, Fascículo 118, Santiago 2005. (Págs. 305 - 345) 
tienen la misma altura y se cubren con bóvedas de crucería, con plementería de sillería y con los nervios y las claves decoradas (Figura 12). Los arcos fajones y torales descansan sobre pilastras y los nervios de las bóvedas terminan en roleos que les sirven de apoyo. El crucero se cubre con otra bóveda similar, pero situada a mayor altura que las antedichas y se remata con una linterna. Las estancias destinadas a sacristías, de menor altura que el presbiterio, también se cubren con bóvedas similares. El resultado al exterior es un conjunto de volúmenes escalonados muy bien diferenciados, sobre el que destaca la alta torre y la cubierta del crucero con la linterna (Figura 13).

En octubre de 1889, se solicita a Sesmero que forme un proyecto para la construcción de un nuevo templo en Santo Tomás de Caldas de Reis, ante el estado de ruina y reducidas dimensiones del antiguo, que se acabará demoliendo. El nuevo se levantará en el mismo lugar que el anterior entre 1890 y $1894^{79}$, según el proyecto de Sesmero.

En la memoria explicativa el arquitecto dedica un apartado a comentar el estado del templo viejo, así como la necesidad del nuevo: sobre el primero opina que "Es de antigua y tosca construcción en su origen; ha sido ampliado con posterioridad, formando un conjunto irregular, pobre y reducido, con aspecto de pajar más que de templo" y "que el desarrollo poblacional y su comercio motivan grandes concurrencias de vecindario (que) en los dias festivos y feirados pone de manifiesto la imperiosa necesidad de un nuevo templo».

La idea de levantar un nuevo edificio ya había sido considerada con anterioridad en varias ocasiones como algo urgente por la diócesis compostelana. En 1865 Juan de Ciórraga había presentado un proyecto para una iglesia de nueva planta que no se llevó a cabo (Figura 14). Este proyecto de Ciórraga presenta una planta casi idéntica a la proyectada por el arquitecto diocesano -antecesor de Sesmero en la diócesis de Santiago-, Faustino Domínguez Domínguez para Santa María de Bertoa (Carballo), en 1866, mientras que la fachada es muy similar a las diseñadas por Manuel de Prado y Vallo para la iglesia de Santiago de Padrón en 1859 y $1867^{80}$.

Sesmero proyecta y realiza, veintidós años después de este proyecto de Ciórraga de lenguaje neoclásico, un templo en estilo neomedieval (Figura 15). Se trata, como en los casos antes analizados, de un neomedievalismo ecléctico que no reproduce modelos concretos sino que solamente evoca formas medievales, en este caso románicas.

${ }^{79}$ A.H.D.S. Fondo general. Templos. C-1.252. Expediente de construcción de un nuevo templo parroquial en Santo Tomás de Caldas de Reyes. 1886-1899. C-1252. Proyecto de Juan de Ciórraga de una iglesia parroquial para Caldas de Reyes. 1865.

${ }^{80}$ Véase SÁNCHEZ GARCÍA, J.A. (1997), 138 a 140. 


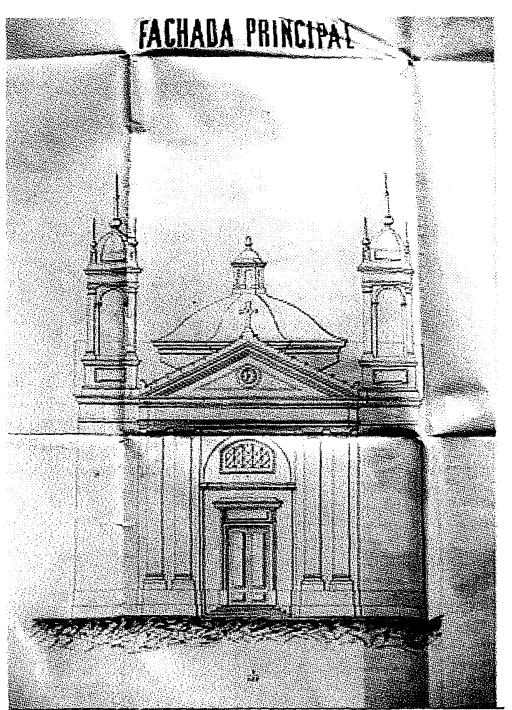

Figura 14.- Fachada del proyecto de Juan de Ciórraga para Santo Tomás de Caldas de Reis.

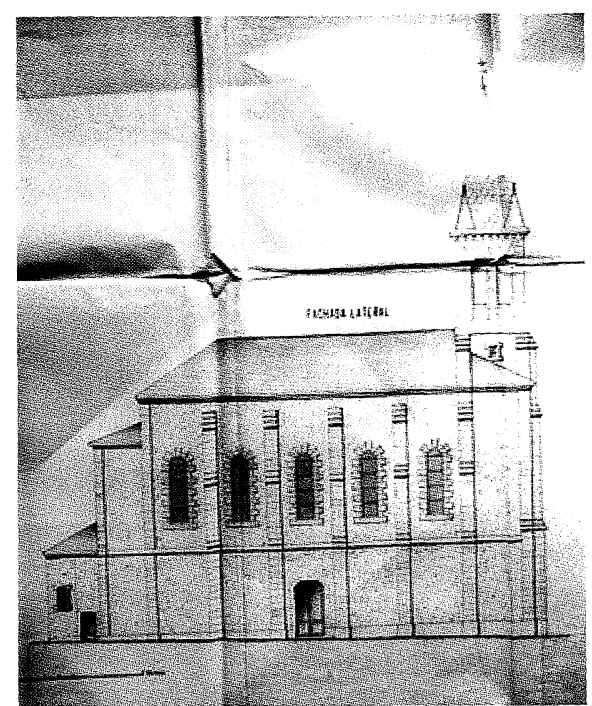

Figura 15.- Alzado lateral del proyecto de Domingo Rodríguez Sesmero para Santo Tomás de Caldas de Reis.

La simplicidad y desornamentación del diseño es total. La planta, de una sola nave se remata por una cabecera poligonal en la que se sitúa el presbiterio y tras éste la sacristía ${ }^{81}$. A los pies hay una estancia que hace de pórtico y a sus lados el baptisterio y la escalera de acceso a la tribuna y la torre. Según se expresa en la memoria: «la forma del templo ha tenido que acomodarse al terreno disponible, aunque no difiera mucho de la que hubiera adoptado teniendo campo libre». Las dimensiones proyectadas eran de 28,60 metros de largo de los pies a la cabecera, 16 metros de ancho en la nave y ocho de ancho por siete de fondo en la cabecera. La adopción de la planta de una sola nave se justifica en la memoria por razones de economía: «Se ha adoptado la forma de una sola y espaciosa nave para evitar el mayor coste de pilares o columnas en el caso de optar por naves laterales, y también con el fin muy plausible de satisfacer el vehemente deseo de los fieles de ver todos al sacerdote durante la celebración de los actos religiosos».

${ }^{81}$ La forma de esta cabecera debió ser alterada durante la construcción, ya que actualmente tiene una planta rectangular, con un presbiterio de planta rectangular, más profundo que el proyectado y a ambos lados de éste dos estancias simétricas adyacentes, desapareciendo la situación de la sacristía que vemos en el plano original. En los muros del presbiterio aparecen unos vanos posiblemente reutilizados del templo viejo u otras construcciones. 
La nave se cubre con bóveda de cañón, que se divide en cinco tramos delimitados por los arcos fajones de sillería que apoyan en gruesas pilastras del mismo material. En el tercer tramo de la nave se abre una puerta lateral en cada uno de los muros. El presbiterio se cubre con otra bóveda de cañón (Figura 16). Los muros interiores son de mampostería -originalmente guarnecidos con mortero, estucados y blanqueados, hoy la mampostería está vista- y en cada tramo se abre una amplia ventana, que junto a las tres de la fachada proporcionan al interior gran luminosidad. La cubierta está formada por armadura de madera y teja de Marsella. El pavimento es de cemento Portland, de losas alternadas negras y blancas, formando un damero.

En el exterior el templo es tan simple y austero como en el interior (Figura 17). Los muros de mampostería -exceptuando la fachada principal- se asientan sobre un zócalo de sillería y están reforzados por contrafuertes, también de sillería lisa, rematados en sencillos pináculos. La fachada principal es toda de sillería fina, así como la torre. El modelo para esta última puede estar de nuevo en los modelos recogidos por Viollet-le-Duc en su Dictionnaire (Figura 18$)^{82}$.

En el diseño de la fachada Sesmero recurre a la misma rígida disposición simétrica vista en San Andrés de Lourizán. La calle central, como en San Andrés, está flanqueada por dos contrafuertes. También se repite la idea de una sola torre colocada en el eje de simetría. El esquema composicional y proporcional seguido es el mismo, pero donde en Lourizán los vanos y arcos son apuntados, en Caldas de Reis son de medio punto y menos moldurados. Además aquí se dividen los dos pisos de la fachada mediante una línea de imposta, que se continúa por los muros laterales, encintando todo el edificio. En la calle central de la fachada hay una segunda línea de imposta que no se extiende a las otras dos calles. Estas líneas cumplen la función de animar el muro además de compensar visualmente la acusada verticalidad del templo, reforzada por la colocación central de la torre y la esbelta aguja. Llama la atención la solución de rematar las calles laterales con un simulacro de frontón que queda interrumpido por la calle central que atravesándolo lo hace desaparecer tras ella. La aguja de la torre, como en Lourizán, es de sillería, tal y como era habitual en los proyectos de Sesmero, como la aguja de San Miguel de Ponteareas, o la de San Marcos de Corcubión.

El estilo austero y funcional del templo se justifica por razones de limitación presupuestaria, como queda reflejado en la memoria: «se nos ha recomendado que

${ }^{82}$ Modelo románico francés del Dictionnaire... ya citado de VIOLLET-LE-DUC, E. (18581868), 320 .

Cuadernos de Estudios Gallegos, Tomo LII, Fascículo 118, Santiago 2005. (Págs. 305 - 345) 


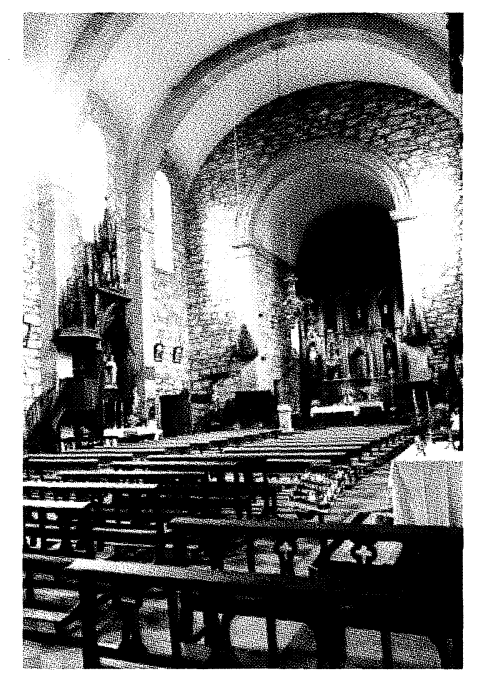

Figura 16.- Santo Tomás de Caldas de Reis. Vista de la nave.

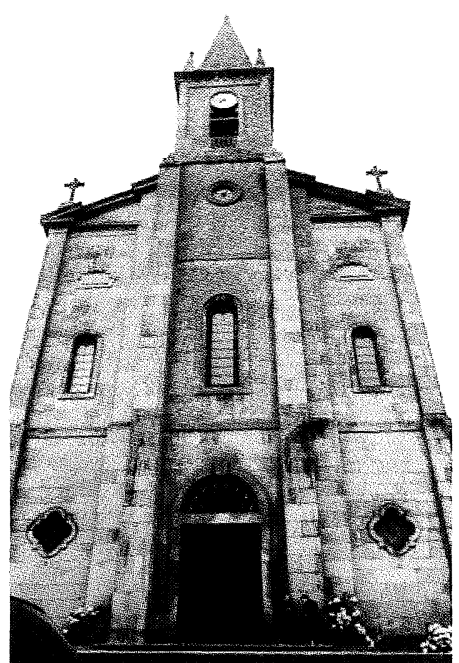

Figura 17.- Santo Tomás de Caldas de Reis. Fachada principal.

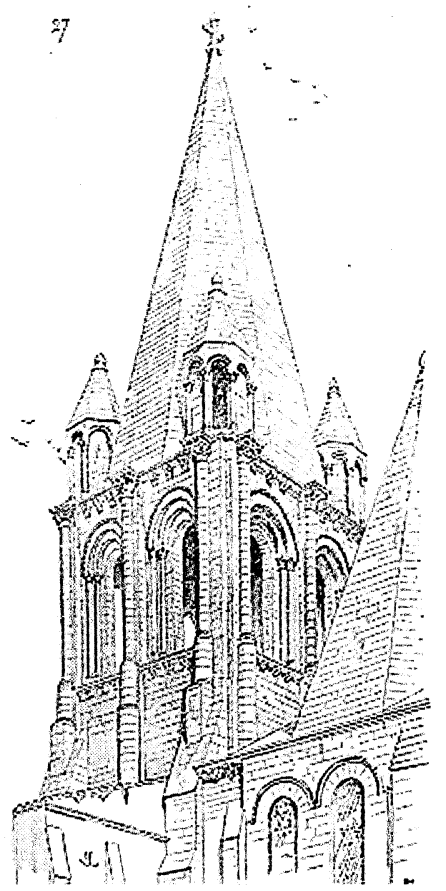

Figura 18.- Torre. Lámina del Dictionnaire... de Viollet-le-Duc. 
la nueva iglesia sea lo más espaciosa posible y sólida, y que a satisfacer estas condiciones se sacrifique todo lujo de ornamentación. La concesión del Estado de 50.000 pesetas es escasa para un templo de tales dimensiones, por lo que el estilo arquitectónico adoptado, como se representa en los demás planos, es en extremo sencillo y severo, así como humilde la clase de fábrica y mano de obra».

El templo costó finalmente 94.556,35 pesetas de las cuales el Estado pagó $66.000 \mathrm{y}$ el resto fue aportado por distintos particulares e instituciones ${ }^{83}$.

Características comunes a todos los templos vistos hasta ahora de autoría de Domingo Rodríguez Sesmero es la concepción simétrica, la simplicidad y claridad en planta y alzado, la colocación de la torre siempre en el mismo lugar, a los pies de la iglesia y en posición central, y la desornamentación tanto interior como exterior. Son todas ellas características que responden a razones de economía y funcionalismo, pero también justificables teniendo en cuenta la formación académica de este arquitecto.

Tenemos en Galicia numerosos ejemplos comparables de neomedievalismo en templos de nueva planta como el ya comentado de San Miguel de Ponteareas (Justino Flórez Llamas, 1881-1890), Santiago de Mondoñedo (Nemesio Cobreros, 18901900), Santa María de los Dolores de Lalín (Nemesio Cobreros, 1899-1929), Santa Eulalia de Valdoviño (1903), Santa Eulalia de Cervo (Nemesio Cobreros, 190607), Santa María de Ferreira (Leoncio Bescansa, 1910). En ellos podemos ver el mismo esquema compositivo básico, que coloca una sola torre en el centro de la fachada y limita la decoración a unos pocos motivos de origen románico (arquillos ciegos lombardos) y góticos (pináculos y agujas decoradas). En todos ellos se aprecia la misma economía decorativa y compositiva. Casos más elaborados son los de San Andrés de A Coruña (F. Domínguez Coumes-Gay, 1881-1884) -en el que puede influir el hecho de ser una obra de patrocinio particular-, o Santiago de Vigo (Manuel Felipe Quintana, 1891-1906).

Las mismas características de composición simple y austeridad decorativa, además de la recurrente colocación de una sola torre en el centro de la fachada vistas en los proyectos de nueva planta de Sesmero se repiten en el otro tipo de trabajos realizados al servicio de la Junta Diocesana de Construcción y Reparación de Templos de la Diócesis de Santiago como son los de consolidación, reparación, ampliación o reconstrucción de partes en ruina, verificada o inminente, en los templos de la circunscripción.

${ }^{83}$ FERNÁNDEZ FERNÁNDEZ, X. (1995), 289. 
En este apartado se puede destacar la intervención realizada en la parroquial de Pontesampaio (Pontevedra), realizada según proyecto de Sesmero en 1893 y cuyas obras se terminan en 1895 .

En la memoria se describe el estilo y estado del templo y las intervenciones que se consideran necesarias ${ }^{84}:$ "Es un edificio bastante antiguo que tuvo origen en la construcción del presbiterio, cobijado por bóveda de piedra sostenida por dos arcos ojivales de estilo Bizantino, y de tosca ejecución. Con larga posterioridad se debió adosar a dicho presbiterio los muros de mampostería ordinaria que forman la nave del templo sobre los que carga la armadura del tejado, de madera sin labra ni otro aderezo que oculte la rusticidad de la techumbre que más parece la de un miserable establo o almacén de carbón que el sagrado lugar destinado a implorar la misericordia divina (...). Las obras que considero necesarias para adecentar el templo a la vez que ampliarle, se reducen a la construcción de cuatro arcos de sillería, repartidos en la longitud de la nave, y de tres en tres metros de uno a otro, adosados a los muros laterales, y de forma igual a la de los dos que existen en el presbiterio, decorados igualmente que éstos en columnas empotradas en el estribo de que hará parte. Dichos arcos de piedra sillería tienen por objeto formar compartimiento a la bóveda que cubre la nave entre los arcos, contribuyendo a quebrantar la monorritmia que resultaría sin ellos la bóveda. Los espacios entre los arcos se cubrirán con bóveda de ladrillo (...). en esta prolongación se satisfarán varios servicios de que carece el templo, que son base para edificar la torre y locales para la escalera que conduzca a ella y al coro, y pila bautismal. En las condiciones facultativas expresamos los materiales y mano de obra que se ha de emplear, con el propósito de no usar lujo en decoraciones, que no permite los recursos destinados al efecto, pero sí se procurará la debida solidez» ${ }^{85}$.

Finalmente los arcos apuntados proyectados en la nave para concordar con los dos antiguos existentes en el presbiterio se realizarán de medio punto (Figura19). En lo demás el edificio tal como lo vemos actualmente responde al proyecto de Sesmero (Figura 20).

La fachada, similar en sus líneas esenciales a la vista en Santiago de Viascón, se divide en tres alturas separadas las dos primeras por una línea de imposta bien remarcada y la tercera por un levísimo retranqueo del plano de fachada. Vertical-

\footnotetext{
${ }^{84}$ A.H.D.S. Fondo general. Templos. C-1254. Expediente de reparación extraordinaria de la iglesia parroquial de Pontesampaio. 1891-1897.

${ }^{85}$ Ibídem.
} 
mente se divide en tres calles, donde las laterales se rematan bajo la cornisa con una decoración de arquillos ciegos, mientras en la central se sitúan la puerta de entrada, bajo un arco de ingreso apuntado, un óculo -seguramente en principio decorado con un sencillo rosetón, como el que hubo en la fachada del templo de Viascón, hoy sustituido por un reloj-y una pequeña ventana apuntada. Coronando esta calle central se coloca la torre, de aspecto macizo y de un solo cuerpo, abierta por vanos apuntados.

Existe en este expediente de Pontesampaio otro proyecto, anterior en dos años al de Sesmero, y firmado por el maestro de obras Andrés de los Reyes ${ }^{86}$. La propuesta de Reyes consiste en un diseño neoclásico (Figura 21) frente al cual se impone el de Sesmero mucho más sencillo y más de acuerdo con el estilo original del edificio. Se puede decir que es éste un caso de aplicación de las ideas de restauración en estilo que habían tenido gran importancia en Francia a raíz de las obras de Eugéne Viollet-le-Duc y que en España se afianzan a partir de finales de los años sesenta del siglo XIX ${ }^{87}$.

Sin embargo no se puede afirmar que Domingo Rodríguez Sesmero tuviese un único criterio a la hora de intervenir en los edificios que se le encargaba restaurar. La idea de mantener el estilo original del edificio lo vemos en la parroquial de Pontesampaio en los años noventa, pero ya lo habíamos visto en San Andrés de Corcubión en 1885. El caso contrario a la solución aplicada en éstos lo tenemos, por ejemplo, en la intervención realizada en la iglesia de Santo Tomé de Piñeiro ${ }^{88}$ (Marín), con proyecto de 1888 , cuyas obras se terminan en 1894. Era ésta una iglesia de época románica con una portada principal abocinada compuesta por un arco apuntado con tres arquivoltas sobre tres columnas a cada lado de la entrada, decoradas con capiteles tallados. Esta portada la reproduce Sesmero en un dibujo en el que muestra las grietas que amenazaban la ruina de la fachada (Figura 22).

Ignorando absolutamente esta portada, Sesmero propone una nueva fachada de tipo clasicista con un frontón sostenido por medio de dos pilastras situadas en los extremos de la fachada, una puerta de ingreso bajo un arco carpanel encuadrado en un marco rectangular cubierto con un guardapolvo horizontal, y sobre ésta un vano semicircular. Sobre el centro de la fachada proyecta la nueva torre, de dos cuerpos y rematada por un cupulín de piedra macizo (Figura 23). Es ésta una fachada telón

${ }^{86}$ Se reproduce el alzado lateral en SÁNCHEZ GARCÍA, J.A. (2001), 217.

${ }^{87}$ ORDIERES DÍEZ, I. (1995), 127. GONZÁLEZ-VARAS, I. (1999), 175.

${ }^{88}$ A.H.D.S. Fondo general. Templos. Expediente de reparación extraordinaria de Santo Tomé de Piñeiro. 1888-1894.

Cuadernos de Estudios Gallegos, Tomo LII, Fascículo 118, Santiago 2005. (Págs. 305 - 345) 


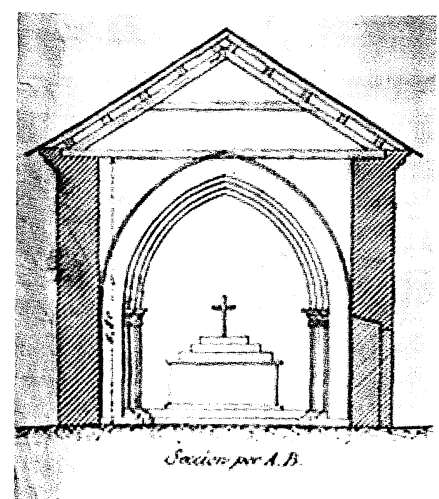

Figura 19.- Sección transversal del proyecto de restauración de la iglesia parroquial de Pontesampaio.

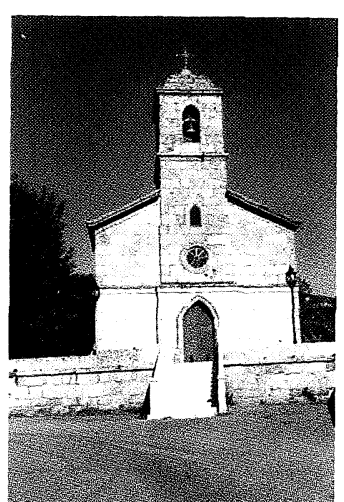

Figura 20.- Parroquial de Pontesampaio. Fachada principal.

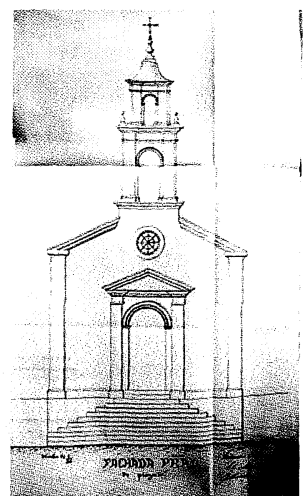

Figura 21.- Fachada del proyecto de Andrés Reyes para la iglesia parroquial de Pontesampaio.

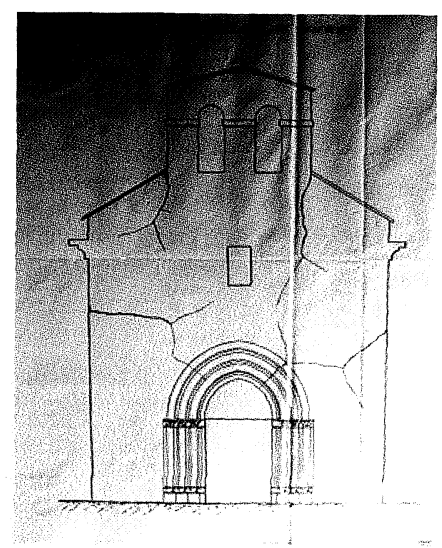

Figura 22.- Plano de la fachada demolida de Santo Tomé de Piñeiro.

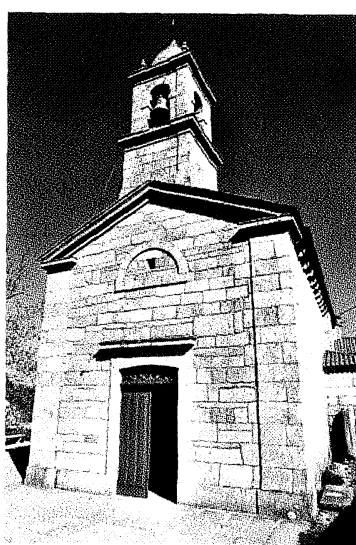

Figura 23.- Fachada actual de Santo Tomé de Piñeiro.

que se antepone al edificio antiguo sin ninguna consideración hacia el estilo original de éste.

Este tipo de fachada la aplica como sencilla solución codificada en numerosos proyectos, como la propuesta para Santa María de Rubianes (Vilagarcía de Arousa), con proyecto de 1884, o la renovación de la fachada de San Gregorio de Raxó 
(Poio) $^{89}$, con proyecto de 1885 (Figura 24). En la memoria del proyecto para la de Rubianes ya aparecían las ideas de restauración en estilo: "Las reparaciones indicadas deben obedecer a completar el pensamiento primitivo de su construcción en los estrechos límites de la consignación otorgada por el Gobierno de S. M. y al mismo tiempo ampliar algo el edificio $»^{90}$. La fachada no se realizó según el proyecto. Esta iglesia aparece hoy día totalmente desfigurada por una intervención posterior que cambió el eje de la nave por uno perpendicular al original, ilustrativa del tipo de intervención irrespetuosa con las preexistencias propia de los años $60 \mathrm{y}$ 70 del siglo XX (Figura 25).

Por último cabe mencionar las intervenciones que se limitan a obras de mera reconstrucción, donde se mantiene prácticamente con exactitud el diseño preexistente en los elementos intervenidos, procediéndose tan sólo a la reparación mediante reposición de elementos dañados, con una talla de la piedra y una disposición de los sillares similar a la anterior. Son los casos, por ejemplo de reconstrucción de fachada y muros de San Lorenzo de Nogueira (Meis) ${ }^{91}$, de 1885-95, inicialmente proyectada con una reedificación de fachada siguiendo la solución tipo-clasicista ya vista, acaba por reconstruirse tal y como era. Otro caso similar es el de la reconstrucción de la torre barroca de San Mamed de la Portela (1887) ${ }^{92}$.

Durante los años que permanece en el cargo Domingo Rodríguez Sesmero interviene también en los expedientes de obras de los siguientes templos parroquiales y conventos de la diócesis de Santiago, bien en declaraciones de ruina, reparaciones de menor importancia artística o terminación de obras iniciadas por su antecesor en el cargo Faustino Domínguez Domínguez ${ }^{33}$ :

- San Lorenzo de Brandeso (Arzúa), $1888^{94}$.

- Santa María de Ciquiril (Cuntis), $1885^{95}$.

${ }^{89}$ A.H.D.S. Fondo general. Templos. C-1259. Expediente de reparación extraordinaria del templo parroquial de San Gregorio de Rajó.

${ }^{90}$ A.H.D.S. Fondo general. Templos. C-1259. Expediente de reparación extraordinaria de Santa María de Rubianes. 1880-1888.

${ }^{91}$ A.H.D.S. Fondo general. Templos. C-1259. Expediente de reparación extraordinaria de San Lorenzo de Nogueira. 1885-1895.

${ }^{92}$ A.H.D.S. Fondo general. Templos. C-1252. Expediente de reparación de la iglesia parroquial de San Mamed de la Portela. 1887.

${ }^{93}$ Se dan sólo las fechas en que Sesmero firma los proyectos correspondientes.

${ }^{94}$ A.H.D.S. Fondo general. Templos. C-1250. Expediente de reparación del templo parroquial de Brandeso.

${ }^{95}$ A.H.D.S. Fondo general. Templos. C-1252. Expediente de reparación extraordinaria del templo parroquial de Santa María de Ciquiril.

Cuadernos de Estudios Gallegos, Tomo LII, Fascículo 118, Santiago 2005. (Págs. 305 - 345) 


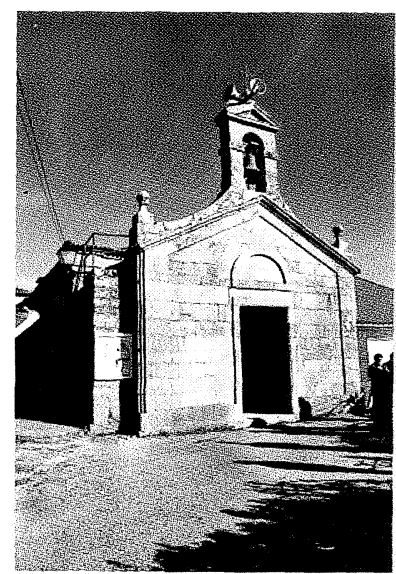

Figura 24.- San Gregorio de Raxó. Fachada.

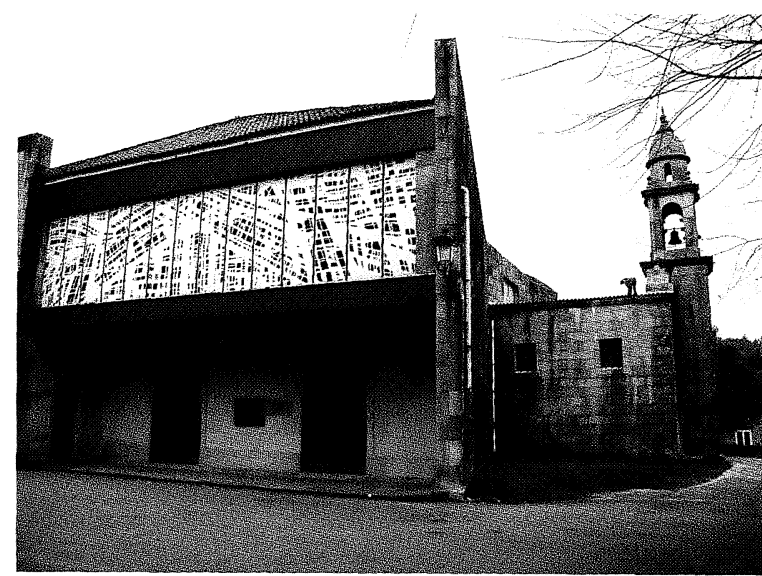

Figura 25.- Santa María de Rubianes.

- Santa María de Beluso (Bueu), $1888^{96}$.

- San Ciprián de Aldán (Cangas), $1887^{97}$.

- Santa María la Antigua del Caramiñal, $1886^{98}$.

- San Juan de Poio, $1888^{99}$.

- Santiago de Pontedeume, $1896^{100}$.

- San Vicente de Aro (Negreira), $1887^{101}$.

- San Vicente de Caamouco (Ares), 1884 ${ }^{102}$.

- Parroquial de Pontecaldelas, $1891^{103}$.

${ }^{96}$ A.H.D.S. Fondo general. Templos. C-1253. Expediente de reparación extraordinaria de la iglesia parroquial de Santa María de Beluso.

${ }^{97}$ A.H.D.S. Fondo general. Templos. C-1253. Expediente de reparación extraordinaria de la iglesia parroquial de Aldán.

${ }^{98}$ A.H.D.S. Fondo general. Templos. C-1256. Expediente de reparación extraordinaria de la iglesia de Santa María del Caramiñal.

${ }^{99}$ A.H.D.S. Fondo general. Templos. C-1259. Expediente de reparación extraordinaria del templo de San Juan de Poyo.

${ }^{100}$ A.H.D.S. Fondo general. Templos. C-1260. Expediente de reparación del templo parroquial de Santiago de Pontedeume.

${ }^{101}$ A.H.D.S. Fondo general. Templos. C-1243 y 1249.

${ }^{102}$ A.H.D.S. Fondo general. Templos. C-1246. Expediente de reparación del templo parroquial de San Vicente de Caamouco.

${ }^{103}$ A.H.D.S. Fondo general. Templos. C-1254. 
- Santa María de Ordes, $1884^{104}$.

- San Juan de Carballo, 1884 105 .

- San Pedro de Muros, $1886^{106}$.

- Santa María de Lira (Carnota), $1885^{107}$.

- Monasterio de Santa Clara de Santiago, $1884^{108}$.

- Convento de Capuchinas de A Coruña, $1885^{109}$.

- Convento de Religiosas de Vista Alegre de Villagarcía, 1884 ${ }^{110}$.

- Convento de Santa Bárbara de A Coruña, 1888 ${ }^{111}$.

- Convento de Dominicas de Belvís de Santiago, $1888^{112}$.

\section{BIBLIOGRAFÍA}

ABEL VILELA, A de. (1996): Urbanismo y arquitectura en Lugo. Arquitectura isabelina y de la Restauración. Ed. Do Castro, Sada, A Coruña.

AZCÁRATE, J.M. (1996): Arte gótico en España. Cátedra, Madrid.

BARREIRO FERNÁNDEZ, X.R. (1991): A sociedade galega contemporánea. Tradición e modernidade. Galicia. Historia. Tomo V. Hércules de ediciones, A Coruña, 1991.

BARREIRO FERNÁNDEZ, X.R. (1997): «Reflexión histórica sobre o marco ideolóxico e as estratexias da igrexa galega no século XIX», en $O$ Feito diferencial galego na Historia. Vol. II. Museo do Pobo Galego. Santiago de Compostela.

CAAMAÑO MARTÍNEZ, J.M. (1962): Contribución al estudio del gótico en Galicia. Universidad de Valladolid, Secretariado de publicaciones, Valladolid.

CANTARELLAS CAMPS, C. (1981): La arquitectura mallorquina desde la Ilustración a la Restauración. Institut d'Estudis Balearics, Palma de Mallorca.

${ }^{104}$ A.H.D.S. Fondo general. Templos. C-1244.

${ }^{105}$ A.H.D.S. Fondo general. Templos. C-1244.

${ }^{106}$ A.H.D.S. Fondo general. Templos. C-1248.

${ }^{107}$ A.H.D.S. Fondo general. Templos. C-1248.

${ }^{108}$ A.H.D.S. Fondo general. Comunidades Religiosas. C-391. Comunidades religiosas y edificios conventuales. Santa Clara.

${ }^{109}$ A.H.D.S. Fondo general. Comunidades Religiosas. C-394. Comunidades religiosas y edificios conventuales. Convento de Capuchinas de A Coruña.

${ }^{110}$ A.H.D.S. Fondo general. Comunidades Religiosas. C-397. Comunidades religiosas y edificios conventuales. Vista Alegra (Agustinas Recoletas)

${ }^{111}$ A.H.D.S. Fondo general. Comunidades Religiosas. C-393 A. Comunidades religiosas y edificios conventuales. Santa Bárbara. (Clarisas). A Coruña.

112 A.H.D.S. Fondo general. Comunidades Religiosas. C-392. Comunidades religiosas y edificios conventuales. Dominicas de Belvís, de Santiago. 
CAPITEL, A. (1988): Metamorfosis de monumentos y teorías de la restauración. Alianza, Madrid.

CARRÉ ALDAO, E. (1928-1935?): Geografia general del Reino de Galicia. Tomo II Alberto Martín ed. Barcelona.

DARDÉ, C. (1996): La Restauración, 1875-1902. Alfonso XII y la regencia de María Cristina. Historia 16, Madrid.

DREXLER, A. (ed.)(1977): The architecture of the Ecole des Beaux-Arts. Secker and Warburg, London.

ESPAÑOL, F. (1989): El arte gótico I. Historia 16, Grupo 16, Madrid.

FERNÁNDEZ FERNÁNDEZ, X. (1995): Arquitectura del eclecticismo en Galicia (1875-1914). Vol.I. Edificación institucional y religiosa. Universidade da Coruña-Xunta de Galicia. A Coruña.

FERNÁNDEZ FERNÁNDEZ, X. (1996): Arquitectura del eclecticismo en Galicia (1875-1914). Vol II. Edificación del ferrocarril, escolar y de recreo. Universidade da Coruña-Xunta de Galicia. A Coruña.

FORNÉS Y GURREA, M. (1846): Álbum de proyectos originales de arquitectura. I. Boix Editor, Madrid.

GARRIDO RODRÍGUEZ, X. e IGLESIAS VEIGA, X.R. (2001): Vigo. Arquitectura urbana. Fundación Caixa-Galicia-Concello de Vigo, Vigo.

GARRIDO RODRÍGUEZ, X. (2000): Arquitectura da pedra en Vigo. Construcciones Conde, Vigo.

GONZÁLEZ-VARAS IBÁÑEZ, I. (1999): Conservación de bienes culturales. Teoría, historia, principios y normas. Cátedra, Madrid.

GONZÁLEZ-VARAS IBÁÑEZ, I. (1996): Restauración monumental en España durante el siglo XIX: teoría, fuentes e ideología. Ámbito ed. Valladolid.

HAUTECOEUR, L. (1955): Histoire de L'architecture classique en France. Ed. Picard, Paris.

HENARES CUÉLLAR, I. (1982): Romanticismo y Teoría del Arte en España. Cátedra, Madrid.

HERNANDO, J. (1989): Arquitectura en España 1770-1900. Cátedra, Madrid.

HITCHCOCK, H-R. (1985): Arquitectura de los siglos XIX y XX. Cátedra, Madrid.

ISAC, A. (1988): Eclecticismo y pensamiento arquitectónico en España. Diputación Provincial de Granada.

LÓPEZ VÁZQUEZ, J.M. (1995): Arte Contemporáneo. Galicia. Arte. Tomo XV. Hércules de ediciones. A Coruña.

MARTÍNEZ ALCUBILLA, M. (1893): Diccionario de la Administración española

MANJARRÉS Y BOFARULL, J. (1862): «Estudios científicos. Conservación y restauración. Iglesias». Revista de Cataluña, 1862, 389-394.

MEYER, F.S. (1965): Manual de ornamentación. Gustavo Gili, Barcelona.

MIDDLETON, R. y WATKIN, D. (1979): Arquitectura moderna. Aguilar, Madrid. 
MIDDLETON, R. (ed.)(1984): The Beaux-Arts and nineteenth-century french architecture. Thames and Hudson, London.

MIGNOT, C. (1983): L'architecture au XIX siècle. Editions du Moniteur-Office du Livre S.A. Fribourg.

NAVASCUÉS PALACIO, P. (1973): Arquitectura y arquitectos madrileños del siglo XIX. Instituto de Estudios Madrileños. Madrid.

NAVASCUÉS PALACIO, P. (1984): La arquitectura gallega del siglo XIX. COAG.

NAVASCUÉS PALACIO, P. (1993): Arquitectura española 1808-1914. Summa Artis, vol XXXV, Espasa-Calpe, Madrid.

ORDIERES DÍEZ, I. (1995): Historia de la restauración monumental en España (1835-

1936). Ministerio de Cultura. Madrid.

PATETTA, L. (1974): La polemica fra i Goticisti e i Classicisti dell'Académie de Beaux-Arts. Cooperativa libraria universitaria del politecnico. Milano.

PATETTA, L. (1977): «Los revivals en arquitectura», en ARGAN, G.C. (coord.): El pasado en el presente. GG.

PONCE COUCE, L. y SÁNCHEZ GARCÍA, J.A.:(1998): Galicia. Guía do patrimonio arquitectónico. Vía Láctea, A Coruña.

RIGALT, L. (1857): Álbum enciclopédico-pintoresco de los industriales. Litografía de la unión. Barcelona. Edición facsímil. Colegio de Aparejadores y arquitectos técnicos. Murcia, 1984.

RUEDA, G. (1996): El reinado de Isabel II. La España liberal. Historia 16, Madrid.

SÁNCHEZ GARCÍA, J.A. (1996): La arquitectura teatral en Galicia. Fundación Pedro Barrié de la Maza, A Coruña.

SÁNCHEZ GARCÍA, J.A. (1997): Faustino Domínguez Domínguez y la arquitectura gallega del siglo XIX. Diputación Provincial de A Coruña.

SÁNCHEZ GARCÍA, J.A. (2001): «Maestros de obras y aparejadores en la época contemporánea», en El Aparejador y su profesión en Galicia. Consello de Aparelladores e Arquitectos Técnicos.

SEITZ, F. (1995): L'école spéciale d'architecture, 1865-1930. Picard, Paris.

SORALUCE BLOND, J.R. (1986): Arquitectura gótica en Galicia. Vigo, COAG.

VIGO TRASANCOS, A. (1990): «A arquitectura da ilustración e do século XIX», en A Arte Galega. Estado da cuestión. Consello da Cultura Galega, A Coruña.

VIOLLET-LE-DUC, E.: Dicctionaire raisonné de l'architecture française du XIe au XVIe siècle. París, B. Bance, 1858-1868. 10 v.

YARZA, J. (1989): El Arte gótico II. Historia 16, nº 19, Grupo 16, Madrid.

YZQUIERDO PERRÍN, R. (1991): «Arte gótico», en Arte Medieval II. Galicia. Arte. Tomo XI. Hércules ediciones. A Coruña. 


\section{ABREVIATURAS}

A.G.A. Archivo General de la Administración. Alcalá de Henares.

A.H.D.T-V. Archivo Histórico Diocesano de Tui-Vigo.

A.H.D.S. Archivo Histórico Diocesano de Santiago de Compostela.

A.D.V. Archivo Diocesano de Valladolid.

A.H.M.C. Archivo Municipal de A Coruña.

A.M.Vi. Archivo Municipal de Vigo.

A.M.V. Archivo Municipal de Valladolid.

A.R.A.V. Archivo de la Real Academia de Bellas Artes de la Purísima Concepción de Valladolid. 